\title{
UNA VISIÓN GENERAL DE LA NUEVA LEY DE CONTRATOS DEL SECTOR PÚBLICO
}

\author{
Eva M. ${ }^{a}$ Menéndez Sebastián \\ Profesora Titular y Catedrática Acreditada de Derecho Administrativo \\ Facultad de Derecho de la Universidad de Oviedo \\ Vocal del Consejo Consultivo del Principado de Asturias \\ menendezeva@uniovi.es
}

\section{RESUMEN}

El pasado 9 de marzo de 2018 ha entrado en vigor la nueva Ley de Contratos del Sector Público. Se trata de una norma de gran complejidad, como, por otro lado, exige la propia materia que regula, y que ba dado un giro importante en algunos aspectos relevantes de la contratación del sector público, en aras de que ésta sea estratégica, profesionalizada y se base en la integridad. Sin romper del todo con la norma anterior, traspone a nuestro ordenamiento el último paquete de Directivas aprobado en 2014. Este trabajo hace un repaso de las principales novedades que la nueva ley ha introducido a lo largo de las cuatro fases de todo contrato: preparación, adjudicación, cumplimiento y extinción, así como, y es quizá lo más destacado, los principios, la perspectiva y los objetivos a que la misma responde.

Palabras clave: Derecho administrativo, contratos del sector público, transparencia, integridad, contratación estratégica, profesionalización, encargos a medios propios.

\section{ABSTRACT}

Last March 9th 2018 the new Contract Act for the Public Sector in Spain has come into force. It is quite a complex law-as required by the subject of study-which has dramatically twisted some relevant aspects of recruitment within the public sector so as to turn it into a strategic, professional and based on integrity issue. Without breaching the previous law it transfers the last set of directives passed in 2014 to our legal system. This study goes through the main novelties the new law has introduced throughout the four stages of any contract: preparation, bid, compliance and termination together with — and more importantly - the principles, perspective and goals the law complies with.

Keywords: Administrative Law, contracts by the public sector, transparency, integrity, strategic recruitment, professionals, own resource errands.

\section{ZUSSAMENFASSUNG}

Am 9. März 2018 trat das neue spanische Gesetz zu Verträgen des Öffentlichen Sektors in Kraft. Es handelt sich um ein Gesetz mit hoher Komplexität, so wie es auch der zu regelnde Gegenstand erforderlich macht; und es bringt in eini- 
gen Aspekten auf dem Gebiet der Vertragsschließung im Öffentlichen Sektor eine wichtige Richtungsänderung mit sich, welche strategisch, professionell und integer zu sein beabsichtigt. Obne die vorhergehende Gesetzgebung komplett hinter sich zu lassen, setzt es das zuletzt verabschiedete Paket von Richtlinien um, die 2014 verabschiedet wurden. Die vorliegende Arbeit bietet eine Durchsicht der wichtigsten Neubeiten, welche das neue Gesetz bezüglich der vier Phasen eines jeglichen Vertrags erbracht hat: die Vorbereitungsphase, die Auftragsvergabe, die Vertragserfüllung und die Beendigung des Vertrags. Ebenso, und das sei vielleicht das Herauszustellende: die Prinzipien, die Perspektive und die Ziele, die dem Gesetz zugrunde liegen.

Schlüsselwörter: Verwaltungsrecht, Verträge des Öffentlichen Sektors, Transparenz, Integrität, Strategische Auftragserteilung, Professionalisierung, Auftragserteilung an eigene Mittel.

SUMARIO: I. VALORACIÓN GENERAL.-II. EL ORIGEN DE LA LCSP: LAS DIRECTIVAS DE CUARTA GENERACIÓN.-III. LAS NOVEDADES MÁS DESTACADAS DE LA LCSP.-1. Cambios relevantes en el ámbito subjetivo de aplicación de la nueva norma.-2. El ámbito objetivo de la LCSP. En especial, la confusión entre los contratos de servicios y las concesiones de servicios.-3. Algunos cambios destacados en los procedimientos de adjudicación.-4. ¿Qué cuestiones será imprescindible tomar en consideración a la hora de confeccionar y aplicar los criterios de adjudicación?-5. Algunas cuestiones a destacar en la regulación del cumplimiento y extinción de los contratos.-6. La extensión del recurso especial en materia de contratos como mecanismo de control.-IV. REFLEXION FINAL.-V. BIBLIOGRAFÍA.

\section{VALORACIÓN GENERAL}

Tras una larga espera, por fin el 9 de marzo ha entrado en vigor la nueva Ley de Contratos del Sector Público (en adelante, LCSP). No sin una ardua tramitación parlamentaria, donde el texto sufrió importantes cambios, el 8 de noviembre vio la luz la Ley 9/2017, dando un margen de cuatro meses, con carácter general, para que las Administraciones y resto de entes del sector público, así como partidos políticos, sindicatos y organizaciones profesionales, sin olvidar tampoco a las empresas y resto de operadores, pudieran adaptarse a los grandes cambios que la entrada en vigor de esta norma conlleva.

Un plazo quizá escaso para tan gran reto, pero tampoco debemos olvidar que este proceso de adaptación comenzó hace ya cuatro años, cuando en 2014 la Unión Europea aprobó el último paquete de Directivas en materia de contratación pública, que debían haber sido traspuestas a nuestro ordenamiento antes del 16 abril de 2016. 
La nueva norma pivota sobre dos grandes ejes que, de un lado, suponen un desafío sin precedentes en la materia, pero que, de otro, abren una ventana de oportunidad para dar cumplimiento al mandato constitucional de una Administración eficaz en la consecución del interés general y, en fin, en dar satisfacción al derecho a una buena administración que proclama la Carta de Derechos Fundamentales de la Unión Europea y que tanto ansiamos los ciudadanos.

El primero de esos ejes es la lucha contra la corrupción. No en vano el art. 1 de la norma comienza recogiendo la idea de integridad, que se materializa como principio no solo ético, sino también con efectos jurídicos a lo largo de toda la norma.

En aras de la consecución de esa «honradez» en la contratación se adoptan diversas medidas de gran calado. Así, basta mencionar la nueva y más estricta regulación de los convenios y de los encargos a medios propios, la apuesta por la transparencia, la regulación de los conflictos de intereses, la profesionalización de las mesas y el fortalecimiento de los controles, destacando la importante expansión que se produce del recurso especial en materia de contratos, pero también la supresión del procedimiento negociado por razón de la cuantía, la publicidad y mayor control respecto a los modificados, la creación de un organismo independiente de supervisión y control (la Oficina Independiente de Regulación y Supervisión de la Contratación) o la apuesta por la uniformidad del régimen jurídico aplicable a todos los poderes adjudicadores. Aunque bien es cierto que, en contraposición, ha resultado un tanto decepcionante la limitada aplicación de la norma a los partidos políticos, sindicatos y organizaciones profesionales, que finalmente se ha impuesto durante la tramitación parlamentaria.

El otro punto fuerte de esta norma gira en torno a la denominada «contratación estratégica», donde los aspectos sociales, medioambientales, de innovación o laborales han adquirido un papel mucho más destacado ${ }^{1}$.

La Unión Europea, consciente de que la contratación pública supone casi el 20 por 100 del PIB, aprovecha la ocasión para concebirla no como un gasto, sino como una inversión y, en gran medida, un instrumento para

\footnotetext{
${ }^{1}$ Sobre este tema, y, en particular, en relación con la llamada «contratación social», ya he tenido ocasión de pronunciarme en E. M. ${ }^{a}$ MenÉndez SEBASTIÁN, «La contratación social. Introducción de cláusulas sociales en la contratación pública según la doctrina del TJCE (caso Beetjes y otros)», en E. GarCía DE EnTERRÍA y R. Alonso García (coords.), Administración y justicia. Un análisis jurisprudencial. Liber Amicorum Tomás-Ramón Fernández, vol. II, Navarra, Thomson-Civitas, 2012, pp. 3403-3428, aunque es cierto que se ha producido una importante evolución desde entonces.
} 
hacer política social, de desarrollo sostenible, así como para dar impulso a la innovación y a las Pequeñas y Medianas Empresas (en adelante, PYMES) (por ejemplo, en este último caso imponiendo como regla general la división en lotes).

La incorporación de manera transversal y preceptiva de criterios sociales y medioambientales, siempre que guarde relación con el objeto del contrato, pasa a ser una obligación, en el entendimiento de que ello proporciona una mejor relación calidad-precio en la prestación contractual, así como una mayor y mejor eficiencia en la utilización de los fondos públicos.

De igual modo, resultan destacables las medidas que se adoptan en la norma en pro de velar por los derechos de los trabajadores de las empresas contratistas, llegando a poder resolverse el contrato a instancia de los representantes de los trabajadores por impago de los salarios o, incluso, y a pesar de los intentos en el Senado por evitarlo, impidiendo el descuelgue salarial.

Sin duda, la nueva ley supone una ocasión irrepetible de apostar por una Administración que se adapta a las demandas de la sociedad y responde eficazmente a sus necesidades, pero el reto para alcanzar ese fin no es desdeñable.

El cambio de paradigma implica una modificación también sin precedentes en la forma de contratar y, por qué no decirlo, un cambio de mentalidad que no es siempre fácil de lograr en una Administración como la nuestra, pero de eso se trata, de pasar de una contratación burocratizada a una contratación estratégica.

En esta línea, como ha apuntado algún autor, considero que hubiera sido adecuado, dada la complejidad de la norma, optar por la elaboración de un «Código de Contratos Públicos», al estilo francés, donde se pudiera dar tratamiento diferenciado a las partes fundamentales en que puede dividirse la materia; así, por ejemplo, de un lado, los contratos, de otro, las concesiones, así como los contratos de los llamados sectores excluidos, etcétera² ${ }^{2}$.

La profesionalización de la contratación y de quienes la ejecutan es absolutamente indispensable ${ }^{3}$. Y es que no será nada sencillo hacer un empleo adecuado de las consultas preliminares. La elaboración de los plie-

${ }^{2}$ J. M. ${ }^{a}$ Gimeno Feliú, «La necesidad de un código de contratos públicos en España. La contratación pública y las PYMES como estrategia de reactivación económica», en J. M. ${ }^{a}$ Gimeno Feliú y M. A. Bernal Blay (coords.), Observatorio de los contratos públicos 2011, Navarra, Civitas, 2012, pp. 27-84.

3 Tal y como bien ha dicho ya la Unión Europea, por ejemplo, en su Recomendación (UE) 2017/1805 de la Comisión, de 3 de octubre de 2017, sobre la profesionalización de la contratación pública, construir una arquitectura para la profesionalización de la contratación pública. 
gos requerirá de grandes técnicos conocedores de la materia; el diseño del baremo a aplicar será una obra de ingeniería jurídica, incluyendo aspectos sociales, laborales, medioambientales y de innovación, sin que ello llegue a distorsionar la competencia y a su vez sirva para hallar la mejor oferta. Valorar el coste de vida del producto será una tarea también de gran dificultad. En cualquier caso, lo que está claro es que optar únicamente por el precio en busca de una mal entendida seguridad jurídica, salvo supuestos excepcionales, es cosa del pasado.

En fin, un gran reto para las Administraciones, pero también una oportunidad para que nuestro país dé respuesta a las imposiciones europeas y a las nuevas demandas sociales ${ }^{4}$.

\section{EL ORIGEN DE LA LCSP: LAS DIRECTIVAS DE CUARTA GENERACIÓN}

Como premisa para comprender los cambios - a mi juicio, profundos en algunos aspectos y, en especial, en cuanto a la orientación misma de esta norma - es importante conocer su origen. Me refiero, sin duda, al nuevo paquete de Directivas, aprobado en $2014^{5}$, del que trae causa la nueva ley española.

Muy brevemente cabe recordar que la contratación pública es objeto de atención y regulación por parte de la Unión Europea, ya desde finales del siglo pasado, por una razón primordial como es la libre competencia.

De este modo, la instauración del mercado único europeo pone en valor la misma y de ahí que para preservarla sea imprescindible introducir

${ }^{4}$ En esta línea J. M. ${ }^{a}$ Gimeno Feliú, «La nueva Ley de Contratos del Sector Público: una ventana de oportunidad para recuperar el liderazgo institucional público con y desde la contratación pública», Observatorio de Contratación Pública, 23 de octubre de 2017, disponible en bttp://www.obcp.es/index.php/mod.opiniones/mem.detalle/id.317/relcategoria.208/relmenu $.3 / c b k . d 2 b 802 d a 721758 c e e e 2 d 2 c 222 c 7 d c 305$.

5 Dentro del que se encuentran la Directiva 2014/23/UE, relativa a la adjudicación de contratos de concesión; la Directiva 2014/24/UE, sobre contratación pública; la Directiva 2014/25/UE, relativa a la contratación por entidades que operan en los sectores del agua, la energía, los transportes y los servicios postales, y la Directiva 2014/55/UE, relativa a la facturación electrónica en la contratación pública. Si bien en el marco de dicha regulación comunitaria es imprescindible tener en cuenta también la Directiva 2007/66/ CE/CEE, sobre recurso en materia de contratos públicos; el Reglamento Delegado (UE) 2015/2170 de la Comisión, por el que se modifica la Directiva 2014/24/UE en lo que se refiere a los umbrales de aplicación en los procedimientos de adjudicación, o el Reglamento (UE) 2016/7, de 5 de enero de 2016, formulario normalizado de documento europeo único de contratación. 
una serie de reglas que afecten también a la contratación de las Administraciones Públicas y, con carácter más general, a entes del sector público —en la idea principal de ser aplicadas cuando hay fondos públicos-. De lo contrario, la competencia en condiciones de igualdad entre las empresas de los distintos países sería imposible.

Ésta fue la causa originaria de que el Derecho comunitario entrara de lleno en la regulación de la contratación pública. Es importante recordarlo, precisamente, porque esa visión ha dado un giro fundamental con las nuevas Directivas, que introducen una perspectiva social, a mi juicio, determinante del resultado final.

La libre competencia, siendo un valor esencial, ya no es el único elemento a tener en consideración, sino que se opta por utilizar la contratación pública como instrumento de política social. No obstante, armonizar ambos aspectos no es una tarea sencilla, y ello puede comprobarse en la gran complejidad que esta norma tiene.

Por otro lado, debe recordarse que el Derecho de la Unión Europea prescinde de la distinción, propia de nuestro país e incorporada al mismo tomando el modelo francés, entre contratos administrativos y privados $^{6}$, lo que, sin duda, también incrementa la complejidad de la norma española.

Es preciso tener en cuenta también que, aunque el sistema español ha superado con creces el plazo de transposición, que concluyó el 16 de abril de 2016, algunas de las previsiones contenidas en dichas Directivas resultaban de aplicación por el efecto directo de las mismas (valga de ejemplo el tema de la división en lotes) ${ }^{7}$.

Muy brevemente, por lo que se refiere a las novedades introducidas por el paquete de Directivas indicado, cabe mencionar que se inspira o responde a la Estrategia 2020, lo que lleva a que se trate de sustituir la visión burocrática por la contratación estratégica, se parta del modelo económico basado en el estándar social y los principios inspiradores sean la eficiencia, la idea de la contratación como instrumental y la integridad.

\footnotetext{
${ }^{6}$ Respecto a la contratación en el sistema francés, cabe remitirse a otros trabajos ya realizados, como, por ejemplo, E. M. ${ }^{a}$ MenÉndez SEbastián, «Régimen jurídico de la contratación pública en Francia», en J. Del Olmo Alonso (dir.), El Derecho de los contratos públicos en la Unión Europea y sus Estados miembros, Valladolid, Lex Nova, 2011, pp. 123-182.

7 A este respecto cabe recordar la recomendación de la Junta Consultiva de Contratación Administrativa sobre el efecto directo de las nuevas Directivas comunitarias en materia de contratación pública (BOE, 17 de marzo de 2016), la recomendación de la JCCA sobre la utilización del Documento Europeo Único de Contratación (BOE, 8 de abril de 2016), el informe JCCA de Cataluña 19/2014 o el informe 3/2015 de la Abogacía del Estado.
} 
Dentro de sus objetivos pueden destacarse: la transparencia en la contratación ${ }^{8}$; la mayor calidad de los contratos públicos — dando un papel destacado a la mejor relación calidad-precio, así como a los criterios de adjudicación distintos del económico-; los objetivos sociales, ambientales, de innovación y laborales; la reducción de la enorme carga burocrática (por ejemplo, a través del documento europeo único de contratación de formato exclusivamente electrónico); potenciar la contratación electrónica; mejorar el acceso de las PYMES a los contratos públicos; dotar de mayor flexibilidad en el uso de la negociación, e incentivar la asociación para la innovación, entre otros.

A modo ejemplificativo, dentro de las principales novedades introducidas por las normas comunitarias cabe aludir: a la extensión de las mismas a ciertos aspectos de las fases de cumplimiento y extinción del contrato; a la aplicación de los principios de las mismas por debajo de los umbrales de la regulación armonizada ${ }^{9}$ y a la regulación de las concesiones, especialmente por lo que se refiere a las de servicios; las etiquetas; las consultas preliminares; la reducción de plazos de publicidad y presentación de ofertas; la generalización de ofertas telemáticas; la distinción entre procedimiento de licitación con negociación y procedimiento negociado sin publicidad previa; la creación de un procedimiento de asociación para la innovación; la posibilidad de no adjudicar el contrato a la oferta económicamente más ventajosa si no cumple con las obligaciones medioambientales, sociales o laborales; nuevas causas de exclusión y plazo no superior a cinco años para las prohibiciones para contratar; la posibilidad de acreditar la solvencia mediante entidades externas, etcétera.

Partiendo de estos mimbres y siendo la norma española bastante fiel a la propia literalidad de la normativa comunitaria, es preciso ahora pasar a analizar las principales novedades introducidas en nuestro sistema por la LCSP.

${ }^{8}$ Vid. al respecto J. M. MARTÍNeZ FernándeZ, Contratación pública y transparencia. Medidas prácticas para atajar la corrupción en el marco de la nueva regulación, Madrid, El Consultor de los Ayuntamientos, 2016.

9 Art. 18. 


\section{LAS NOVEDADES MÁS DESTACADAS DE LA LCSP}

\section{Cambios relevantes en el ámbito subjetivo de aplicación de la nueva norma}

Por lo que al ámbito subjetivo se refiere, dentro de las novedades caben destacar, a mi juicio, algunas cuestiones de gran relevancia.

En primer lugar, y en cuanto a los sujetos a los que es de aplicación la nueva ley, siguiendo el ejemplo de su predecesora y de otras normas recientes, como la Ley 40/2015, de 1 de octubre, de Régimen Jurídico del Sector Público (en adelante, LRJSP), mantiene la complejidad y las dudas respecto a los sujetos y el grado de aplicación a los mismos ${ }^{10}$. Así, sigue partiendo de los tres círculos concéntricos: sector público, poder adjudicador y Administración Pública ${ }^{11}$, si bien introduce ciertas novedades.

Entre ellas cabe advertir la inclusión de los partidos políticos, las organizaciones sindicales y las organizaciones empresariales y asociaciones profesionales, así como las fundaciones y asociaciones vinculadas a cualquiera de ellos, cuando cumplan los requisitos para ser poder adjudicador ${ }^{12} \mathrm{y}$ respecto de los contratos sujetos a regulación armonizada. Si bien con la redacción dada finalmente y tras el debate parlamentario al respecto se ha limitado dicho sometimiento a la ley, a mi juicio de forma decepcionante, puesto que en este caso se reduce a la aprobación de unas instrucciones internas en materia de contratación ${ }^{13}$.

${ }^{10}$ Como advierte, entre otros, J. M. ${ }^{a}$ Gimeno Feliú, «Aproximación a las principales novedades de la Ley de Contratos del Sector Público», Revista Aragonesa de Administración Pública, núm. extra 10 (2008), p. 23, quien califica de barroca la transposición de las Directivas - anteriores- en este aspecto.

${ }^{11}$ Como recuerda B. Noguera DE la Muela, «El ámbito subjetivo de aplicación de la Ley 9/2017, de 8 de noviembre, de Contratos del Sector Público. Compra conjunta y centrales de compra», en J. M. . Gimeno Feliú (dir.), Estudio sistemático de la Ley de Contratos del Sector Público, Navarra, Thomson Reuters, 2018, p. 250.

${ }^{12}$ Es decir, han de cumplirse tres requisitos. El primero de ellos, que tenga personalidad jurídica propia, ya sea de Derecho público o privado; en segundo lugar, que haya sido creado para satisfacer necesidades de interés general que no tengan carácter industrial o mercantil, y, finalmente, una de las tres cuestiones siguientes, a saber, que otro poder adjudicador financie mayoritariamente su actividad, controle su gestión o nombre a más de la mitad de los miembros de su órgano de administración, dirección o vigilancia.

${ }^{13}$ Las cuales, de acuerdo con el art. 3.4 LCSP, deberán adecuarse tanto a la normativa comunitaria como a los principios de publicidad, concurrencia, transparencia, igualdad y no discriminación. 
No está exenta de dudas, a mi juicio, la última previsión del art. 3, es decir, la mención que en su apartado 5 se hace a las corporaciones de Derecho público, puesto que somete a las mismas a la ley también cuando cumplan los requisitos para poder ser poder adjudicador de acuerdo con la letra $d$ ) del apartado 3.3. Es decir, cuando además de haber sido creadas específicamente para satisfacer necesidades de interés general que no tengan carácter industrial o mercantil, uno o varios sujetos que deban considerarse poder adjudicador financien mayoritariamente su actividad, controlen su gestión o nombren a más de la mitad de los miembros de su órgano de administración, dirección o vigilancia.

Ello lleva, por ejemplo, a plantearse qué supuestos podrían comprenderse en dicho apartado. Así, difícilmente encajan los colegios profesionales, pues la mayor parte de sus ingresos provienen de las cuotas de sus colegiados ${ }^{14}$.

Además, en aquellos supuestos en que pudieran darse los requisitos mencionados, la duda vendría del grado de sometimiento a la ley, pues ésta no clarifica si se les aplicaría la misma con igual intensidad que a cualquier poder adjudicador o, por el contrario, como en el caso de los partidos políticos, sindicatos y asociaciones profesionales, deberían aprobar instrucciones internas.

En cambio, entiendo que es positiva la supresión a la mención de que las entidades públicas empresariales no son Administración Pública, optando por el criterio de que solo las entidades de Derecho público que sean efectivamente de mercado serán no Administración a efectos de la $\operatorname{LCSP}^{15}$.

De igual modo, resulta destacable que se considere poder adjudicador a todo medio propio, pues con ello se pretende evitar que por esta vía se eludan las reglas de contratación ${ }^{16}$.

Por otro lado, los órganos constitucionales y equivalente autonómicos también tienen la consideración de Administración Pública a efectos de la ley, tal y como prescribe la disposición adicional cuadragésima cuarta ${ }^{17}$.

${ }^{14}$ En esta línea ya apuntó el TJUE en relación al Colegio de Médicos de Westfalia-Lippe en su Sentencia de 13 de septiembre de 2013, asunto C-526/11. Con carácter general vid. J. A. Moreno Molina, El nuevo Derecho de la Contratación Pública de la Unión Europea. Directivas 4.0, Oxford, Chartridge Books Oxford, 2015, pp. 154-156.

${ }^{15}$ En línea con la estela marcada por la Ley 40/2015, de 1 de octubre, de Régimen Jurídico del Sector Público.

${ }^{16}$ Siguiendo de este modo la doctrina del TJUE, por ejemplo, en la Sentencia de 5 de octubre de 2017, caso UAB LitSpecMet.

${ }^{17}$ Se trata de una muestra más de la cantidad, a mi juicio excesiva, de cuestiones que se han llevado a las disposiciones, cuando muchas de ellas son propias del articulado. 
Por otra parte, a mi juicio, una de las principales novedades de la nueva ley es la referente al endurecimiento de los requisitos para adquirir la condición de medio propio, así como el régimen jurídico de los encargos que puedan hacerse a los mismos al margen de dicha norma ${ }^{18}$. Además recuérdese que, como bien ha indicado la mejor doctrina, el fundamento de esta exclusión se encuentra en la capacidad autoorganizativa de las Administraciones Públicas ${ }^{19}$, resultando irrelevante el reconocimiento de una personalidad jurídica independiente, que es tan solo una herramienta que no significa la desvinculación de la organización empresarial de las entidades públicas de que trae causa ${ }^{20}$.

El art. 86 LRJSP — que no tiene carácter básico - remite al Texto Refundido de la Ley de Contratos del Sector Público (en adelante, TRLCSP) (hoy LCSP) a efectos de conocer cuándo un ente puede considerarse medio propio, pero, además, tendrá la consideración de medio propio y servicio técnico cuando se acredite que, aparte de disponer de medios suficientes e idóneos para realizar prestaciones en el sector de actividad que se corresponda con su objeto social de acuerdo con su norma o acuerdo de creación, se dé alguna de las circunstancias siguientes: a) sea una opción más eficiente que la contratación pública y resulte sostenible y eficaz, aplicando criterios de rentabilidad económica, o $b$ ) resulte necesario por razones de seguridad pública o de urgencia en la necesidad de disponer de los bienes o servicios suministrados por el medio propio o servicio técnico.

18 Respecto a este tema vid., entre otros, F. SOSA WAGNER y M. FuerTEs LóPEZ, «¿Pueden los contratos quedar en casa? La polémica europea sobre la contratación in house», La Ley, núm. 3 (2007), pp. 1669-1680; J. GONZÁLEZ GARCÍA, «Medios propios de la Administración, colaboración interadministrativa y sometimiento a la normativa comunitaria de contratación», RAP, núm. 173 (2007), pp. 217-237; M. ${ }^{a}$ R. SANZ CEREzo y A. MARTín GALLEGo, «La regulación de los medios propios en la nueva Ley de Contratos del Sector Público», El Consultor de los Ayuntamientos y de los Juzgados, núm. 1 (2018), pp. 111-119, y M. A. FrANCO-GARCíA, «Propósitos y despropósitos sobre los encargos de los poderes adjudicadores a medios propios instrumentales en la Ley de Contratos del Sector Público», Contratación administrativa práctica: revista de la contratación administrativa y de los contratistas, núm. 154 (2018), pp. 6-18.

19 Es el caso del profesor F. SOSA WAGNER, «El empleo de recursos propios por las Administraciones locales», en L. Cosculluela Montaner (coord.), Estudios de Derecho Público Económico. Libro bomenaje al profesor S. Martín-Retortillo, Madrid, Civitas, 2007, p. 1317.

20 En esta línea A. Huergo LorA, «La libertad de empresa y la colaboración preferente de las Administraciones Públicas con empresas públicas», RAP, núm. 154 (2001), p. 130, destaca que la existencia de personalidades jurídicas diferenciadas juega en el plano formal y que afecta solo a la Administración, no siendo relevante en el plano de las relaciones intersubjetivas. Añadiendo que: «Desde esta perspectiva el problema es saber si, y hasta qué punto, se adaptan a una situación de este tipo técnicas como el contrato que presuponen una dualidad efectiva de sujetos y de centros de intereses, es decir, si son verdaderos contratos esos negocios en los que realmente no existe una oposición de intereses entre los dos sujetos que los celebran». 
También añade que formará parte del control de eficacia de los medios propios y servicios técnicos la comprobación de la concurrencia de los mencionados requisitos. Y que en la denominación de las entidades integrantes del sector público institucional que tengan la condición de medio propio deberá figurar necesariamente la indicación «Medio Propio» o su abreviatura $\ll M P »$.

Asimismo, a la propuesta de declaración de medio propio y servicio técnico deberá acompañarse una memoria justificativa que acredite lo dispuesto en el apartado anterior y deberá ser informada por la Intervención General de la Administración del Estado que vaya a declarar el medio propio y servicio técnico. Cabe deducir varias conclusiones del citado precepto, aunque solo sea aplicable a la Administración General del Estado y su sector público, si bien, con carácter supletorio, sí puede afectar al resto de Administraciones.

Por un lado, que para crear un medio propio con los requisitos que la LCSP exige, a los que seguidamente aludiré, es necesario que se trate de una opción más sostenible económicamente que la contratación —salvo casos excepcionales de seguridad pública o de urgencia-y que dispongan de los medios idóneos para hacer las prestaciones en ese sector y le sean propias en función de su objeto social.

De otro lado, parece que se opta porque haya suficientes controles como para comprobar y fiscalizar que eso es así.

Por otra parte, son los arts. 32 y 33 LCSP los que regulan ahora los requisitos para entender que un ente es medio propio de un poder adjudicador:

En primer lugar, es necesario que exista un control análogo a sus propios servicios, lo que implica que ejerza una influencia decisiva sobre sus objetivos estratégicos y decisiones significativas, además de poder conferirles encargos de ejecución obligatoria, lo que debe constar en sus estatutos o acto de creación.

También resulta importante que se mantenga la compensación por tarifas previamente aprobadas y que han de responder a costes reales, pues se trata de un requisito, a mi juicio, relevante, pero que, no obstante, ha desaparecido con las nuevas Directivas, cuya regulación en las mismas responde a la consolidación de la doctrina de los contratos in house que ha venido estableciendo el Tribunal de Justicia de la Unión Europea (en adelante, TJUE) ${ }^{21}$.

${ }^{21}$ A este respecto vid., por ejemplo, B. Noguera de la Muela, «Los encargos in house en la Ley de Contratos del Sector Público (LCSP): especial referencia a los mismos en el 
En segundo lugar, ha de desarrollar el 80 por 100 de su actividad para el poder adjudicador del que es medio propio, lo que ahora se acredita con las cuentas anuales de los tres últimos ejercicios ${ }^{22}$.

Además, se establece una limitación, ya en parte recogida en el TRLCSP, aunque no en los mismos términos. Me refiero a que en la actualidad se especifica que si se trata de personificación jurídico-privada, el 100 por 100 del capital o patrimonio ha de ser de titularidad pública.

No obstante, la diferencia estriba en que con anterioridad dicho requisito se limitaba a las sociedades, mientras que la nueva norma habla de «personificación jurídico-privada» y no solo de capital, sino también de patrimonio, por lo que cabe - cuanto menos- plantearse si dicho requisito no se ha extendido a otros supuestos, como, por ejemplo, las fundaciones privadas.

Finalmente, es preciso también que se reconozca expresamente la condición de medio propio en los estatutos o acto de creación con dos requisitos previos, como son la conformidad o autorización expresa y la verificación de medios adecuados.

En el caso de ser medio propio de varios poderes adjudicadores, los requisitos son los mismos; no obstante, en cuanto al control análogo, se entiende que se da cuando hay un control conjunto, lo que sucede cuando en los órganos decisorios del ente destinatario del encargo están representados todos los entes que hacen el encargo, que ejerzan directamente o en conjunto una influencia decisiva y que no persigan intereses contrarios a los propios de los entes que hacen el encargo.

Pero además de endurecerse los requisitos, también destacan algunas novedades de régimen jurídico del encargo, ya que se ha de publicar en la Plataforma de Contratación de qué entes es medio propio y sectores de actividad de cada uno de ellos; la formalización del encargo en documento se publica también en la Plataforma ${ }^{23}$; los límites a la contratación por el medio propio para ejecutar el encargo se hará con sometimiento a la $\mathrm{LCSP}^{24}$, de ahí que en todo caso deba ser poder adjudicador también

ámbito local a la luz de la reciente jurisprudencia comunitaria», RAP, núm. 182 (2010), pp. 159-190.

${ }^{22}$ Calculado del modo que indica la propia LCSP y, en caso de tratarse de entes de reciente creación, a través de otros mecanismos.

${ }^{23}$ Siempre que supere los 50.000 euros y desde esa cuantía hasta los 5.000 al menos trimestralmente y por identidad del medio propio, tal y como establece el art. 63 LCSP al regular lo que ha de publicarse en el perfil del contratante.

${ }^{24}$ Recuérdese que, de acuerdo con el art. 37 LCSP, puede a su vez encargar a un tercero hasta un 50 por 100 de la prestación. 
el medio propio, y además son susceptibles de recurso especial cuando se considere que realmente no cabe encargo a medio propio, sino aplicación de la LCSP.

\section{El ámbito objetivo de la LCSP. En especial, la confusión entre los contratos de servicios y las concesiones de servicios}

Por lo que al ámbito objetivo se refiere, junto a la importante novedad de la supresión de los contratos de colaboración público-privada y de gestión de servicios públicos, a los que dedicaré unas líneas más adelante, se hacen una serie de precisiones respecto a los contratos excluidos con mayor detalle que su predecesora. A ello dedica la LCSP los arts. 4 a 11, y entre las cuestiones previstas en ellos destacan, por ejemplo, los convenios y encomiendas de gestión o los contratos de investigación, desarrollo e innovación.

Respecto a estos últimos, aunque con una redacción muy poco afortunada, la ley se hace eco de la exclusión contenida en la Directiva respecto a ciertos servicios de este tipo ${ }^{25}$, siempre que se compartan riesgos y beneficios, es decir, cuando no se financien de forma exclusiva por el poder adjudicador y los beneficios tampoco le pertenezcan a él únicamente ${ }^{26}$.

Sin duda, el objetivo es fomentar la cofinanciación de los programas de investigación y desarrollo por parte de la industria ${ }^{27}$. No obstante, como bien ha indicado la doctrina, ha de tenerse en cuenta que solo queda excluida la provisión de soluciones de innovación totalmente nuevas o sustitutivas de otras menos eficientes y que alcanza a todas las fases de comercialización, pero no los productos finales, es decir, no quedaría excluida la adquisición de obras, bienes o servicios acabados y operativos para satisfacer de modo inmediato una necesidad pública ${ }^{28}$.

Teniendo en cuenta, además, que el precepto en cuestión no hace precisión alguna respecto al sujeto contratante, debe entenderse que este tipo

\footnotetext{
${ }^{25}$ Los expresamente mencionados en el art. 8, que se concretan con indicación del Código CPV.

${ }^{26}$ En relación con la posibilidad de ayudas o subvenciones vid., por ejemplo, el Informe de la JCCA 3/2011, de 10 de mayo de 2012, o la Guía 2.0 para la compra pública de innovación, de junio de 2015, en especial pp. 63-66.

${ }_{27}$ Tal y como la propia Directiva reconoce en su considerando 35.

${ }^{28}$ En palabras de A. LÓPEZ MiÑo, «La contratación precomercial en el Derecho de la Unión Europea. El reparto de riesgos y beneficios y la cuestión de las ayudas de Estado», Revista de la Escuela Jacobea de Posgrado, núm. 2 (2012), p. 75.
} 
de contratos pueden ser celebrados tanto por entes que sean Administración como por aquellos que carezcan de tal condición ${ }^{29}$.

De otro lado, la exclusión de la LCSP no implica que no deban someterse a los principios de la misma y, en especial, al de transparencia, dado que este se recoge también en el art. 3 LRJSP ${ }^{30}$. Es más, la propia LCSP remite a los principios de la misma en los contratos excluidos ${ }^{31}$.

Sin embargo, a mi juicio, una de las principales novedades de la LCSP en cuanto al ámbito objetivo de la misma es la introducción de la concesión de servicios y su confusión con el contrato de servicios.

Si ya se ha tenido ocasión de exponer en otros trabajos la debilidad de la que viene adoleciendo la figura de los contratos de servicios desde el plano conceptual de la misma, que se debe tanto a sus humildes orígenes como, en los últimos años, a un abandono de la tradición de nuestro sistema, así como del francés — del que hemos tomado ejemplo en materia de contratación-, para aproximarse a una trasposición cuasiliteral de las Directivas comunitarias, esta situación se ha visto considerablemente agravada con la nueva LCSP.

Y es que, en la delimitación de las categorías contractuales, la ley española ha venido apartándose de su propia tradición para incorporar sin más la clasificación europea, que no atiende, ni mucho menos, a los mismos criterios que en origen se tuvieron en cuenta por nuestro ordenamiento.

Esta aproximación ha llegado, por el momento, a su culmen con la confusión que la nueva LCSP hace respecto a los contratos de servicios y la concesión de servicios. Como es bien conocido, las Directivas de 2014 en cierta medida se hicieron eco por primera vez de las concesiones, a las que se dedica la Directiva 2014/23/UE, de 26 de febrero.

Muy al contrario, nuestro sistema ya preveía este contrato en las normas anteriores, aunque denominado como gestión de servicio público. Para entenderlo es preciso partir de que los diversos Estados miembros

${ }^{29}$ De esta opinión son R. Fernández Acevedo y P. VALCÁRCEl FernándeZ, «La problemática cuestión de la competencia del orden contencioso en relación con los contratos de compra pública precomercial», en Observatorio de los Contratos Públicos. Las nuevas Directivas de Contratación Pública, Navarra, Thomson Reuters, 2015, p. 271.

${ }^{30} \mathrm{Tal}$ y como recuerdan M. A. BERNAL BLAY, «Principios de adjudicación de los contratos de servicios de investigación y desarrollo previos a la comercialización (o compra pública precomercial)», en J. M. ${ }^{a}$ Gimeno Feliú y M. A. Bernal Blay (coords.), Observatorio de contratación pública 2013, Navarra, Thomson Reuters, 2014, p. 285, y R. FeRnÁNDEZ AcEVEDO, «Negocios y contratos excluidos», en J. M. ${ }^{a}$ GIMENO Feliú (dir.), Estudio sistemático de la Ley de Contratos del Sector Público, Navarra, Thomson Reuters, 2018, pp. 303-304.

${ }^{31}$ Art. 4. 
de la Unión no cuentan en sus tradiciones jurídicas necesariamente con un concepto clásico de servicio público, propio del modelo francés y del nuestro, pero ajeno en otros sistemas.

Esto lleva a que necesariamente el enfoque de las Directivas de contratos a la hora de prever esta modalidad contractual se aleje de conceptos básicos para nosotros, dado que la razón de esta nueva previsión europea es que, a la vista de aquellos países donde existía este concepto y la gestión indirecta mediante contratos de servicios públicos, era preciso extender los efectos de las Directivas para evitar que esa contratación quedara al margen de los principios básicos de las mismas. Es más, ello se aprecia cuando la propia LCSP en su Preámbulo explica que las concesiones de servicios no se prevén exclusivamente para los servicios públicos, siendo posible que amparen otros distintos ${ }^{32}$.

Ello tiene, entre otras consecuencias, el efecto de romper con la distinción arraigada en nuestro sistema y en otros como el modelo francés entre el objeto contractual propio del contrato de servicios y el del contrato de gestión de servicio público, que pasa a denominarse, con la nueva normativa, de concesión de servicios.

Sin embargo, como ya se ha adelantado, a mi modo de ver de forma muy poco acertada, en la LCSP la definición del contrato de servicios sigue prácticamente intacta respecto a la normativa anterior, basándose en la exclusión respecto a las obras y suministros. Lo que contribuye de forma más intensa a su indefinición, dado que si ya con la normativa anterior se entendía que existía una importante deficiencia que impregnaba su concepción y, en consecuencia, conllevaba la dificultad de delimitarla respecto de otras figuras propias de esta rama del Derecho, pero también de otras disciplinas como el Derecho civil, el laboral o el mercantil, hoy todo ello se ha visto incrementado con la nueva LCSP.

En primer lugar, y teniendo en cuenta que la LCSP ofrece como único parámetro la definición por exclusión de los suministros y las obras, merece la pena hacer una breve referencia a ambas categorías. Aunque, como se expondrá, las notas principales de los contratos de servicios, y, en concreto, su carácter instrumental, se desvanece con la nueva LCSP y su confusión con la concesión de servicios.

Así, en primer lugar, y por lo que se refiere a los contratos de suministros, pudiera parecer que poco o nada tienen en común estas dos figuras, pero esto no es así, puesto que ambas responden básicamente a proveer a

32 Vid. el punto IV de la misma. 
las Administraciones de aquello de lo que carecen y que es imprescindible para el cumplimiento de sus fines. Es decir, son contratos instrumentales en el sentido de constituir habitualmente una fase previa a la realización de una operación. Al menos lo eran hasta la nueva regulación de los contratos de servicios, pues, como se verá, ahora engloban también prestaciones directas a favor de la ciudadanía.

Efectivamente, hasta la nueva regulación, en el caso de los contratos de servicios se pretendía cubrir aquellas carencias, especialmente de tipo personal, que impiden a la Administración llevar a cabo sus obligaciones, por tratarse, en muchos casos, de actividades que por su alto componente intelectual, así como por el grado de conocimiento y especialidad y la titulación que se exige del contratista, deriva en la ausencia de personal funcionarial o laboral que disponga de tales características, pero también físico o material en el resto de supuestos de servicios, y siempre que sea de carácter excepcional u ocasional, en el sentido de no tratarse de una necesidad constante que llevaría a la obligación de dotar de una plaza en la plantilla.

En efecto, otra nota relevante de estos contratos es la falta de generalidad, homogeneidad y habitualidad suficientes para incrementar la plantilla existente en aras de dar respuesta a las mismas, y por lo cual se estima más conveniente acudir a la vía externa de la contratación administrativa para cada caso en que sea necesario.

Del mismo modo, el suministro es un contrato instrumental encaminado a proveer a las Administraciones de bienes y servicios imprescindibles para el cumplimiento de sus fines ${ }^{33}$, es decir, se trata de cubrir necesidades de tipo material a los entes públicos que carecen de lo suficiente para llevar a cabo su actuación. Por tanto, su similitud con los contratos de suministros radicaba en que se trataba en ambos casos de contratos instrumentales a través de los cuales la Administración ve satisfechas sus necesidades y carencias internas. No se trataba de prestar un servicio al ciudadano por medio del contratista, como en el viejo contrato de gestión de servicios públicos, ni ejecutar una actividad que le corresponde a la Administración, como la realización de una obra, sino prestar los medios materiales y personales necesarios para que el ente público ejecute la actividad correspondiente.

33 Vid. F. Sosa Wagner, El contrato público de suministro, 2. a ed., Madrid, Civitas, 2003, p. 40, y L. Tolivar Alas, «Del contrato de suministro», en Comentarios a la Ley de Contratos de las Administraciones Públicas, 2. ${ }^{a}$ ed., Barcelona, Cedecs, 1996, pp. 191-192, entre otros. 
Esta característica, que era imprescindible a la hora de definir estas dos figuras contractuales, encontraba su punto de divergencia en el diferente tipo de carencias que se suplen por una y otra vía, puesto que por medio del contrato de suministro se da respuesta a necesidades de carácter material ${ }^{34} \mathrm{y}$ en el de servicios son de tipo personal y de conocimientos. Sin embargo, esto no evita que en algún supuesto pueda existir confusión o, al menos, poca claridad, como ocurre con los contratos de suministros de sistemas y programas informáticos ${ }^{35}$.

Dicho esto, es evidente que la introducción de la posibilidad de ejecutar prestaciones directas a favor de la ciudadanía — que introduce el art. 312 de la nueva LCSP — ha venido a romper por completo con la característica principal de estos contratos —su carácter instrumental-. No obstante, de ello no se halla reflejo alguno en el art. 17 a la hora de definir esta categoría, sino que se deduce de lo dicho en el art. 312.

Sin duda, a mi juicio, y aun no estando de acuerdo con que fuera necesario romper por completo con nuestra tradición para trasponer adecuadamente las Directivas, al menos debería haberse hecho mención también a la concesión de servicios en la definición por exclusión que prevé el art. 17, pues no es cierto que toda prestación de hacer consistente en el desarrollo de una actividad o a la obtención de un resultado distinto de una obra o suministro sea un contrato de servicios, sino que podrá ser también una concesión de servicios.

Sin embargo, y aun pudiendo ser objeto de ambas figuras prestaciones similares en función de las circunstancias, principalmente de que haya o no riesgo operacional, lo cierto es que en nada se parecen las definiciones ofrecidas en los arts. 15 y 17, respectivamente.

Y llama la atención que se considera bastante más acertada la referente a la concesión de servicios ${ }^{36}$, lo que pone de relieve nuevamente la

${ }^{34}$ Estas necesidades se refieren al material que la Administración necesita y no a actividades de carácter material propias de los contratos de servicios.

35 Este supuesto es debatido por la doctrina, ya que hubiera sido preferible darle la regulación específica que su condición particular reclama, especialmente en lo que se refiere a la distinción entre la compra o arrendamiento de sistemas informáticos y programas ya elaborados y el encargo de unos específicos para la Administración. Precisamente, en la nueva LCSP, en su art. 308, referente al contenido y límites de esta figura contractual, se han introducido en fase de tramitación en las Cortes Generales ciertas precisiones en relación con los servicios que impliquen el desarrollo o mantenimiento de aplicaciones informáticas, lo que, sin duda, con la implementación de la Administración electrónica será esencial.

${ }^{36}$ En efecto, en la definición que se hace de la concesión de servicios en el art. 15 se menciona expresamente que se trata de la gestión de un servicio cuya prestación sea de titularidad o competencia del poder adjudicador que lo encarga y que la contraprestación 
poca atención que se les viene prestando a los contratos de servicios desde sus comienzos.

Por tanto, de una simple lectura de los preceptos de la LCSP referentes a la definición de los diversos contratos de los que se hace eco, es decir, los arts. 12 a 18, nada hace pensar que el objeto de los contratos de servicios haya variado ni tampoco la concepción de los mismos. Sin embargo, es a la hora de analizar el nuevo texto normativo en su conjunto, cuando se puede apreciar que sí ha habido importantes novedades en la definición misma de los contratos de servicios. Aunque bien es cierto que la explicación se halla principalmente en el Preámbulo de la norma.

Así, y de forma muy relevante, como ya se ha avanzado, el art. 312 se refiere en clara alusión, aunque no lo haga expresamente, a aquellas prestaciones que pudiendo ser propias de una concesión de servicios no lo serán por no cumplir con los requisitos establecidos en la norma para ello, es decir, principalmente el riesgo operacional ${ }^{37}$, dado que prevé las especialidades de los contratos de servicios que conlleven prestaciones directas a favor de la ciudadanía.

Previsiones éstas que, sin duda, recuerdan el régimen propio de los antiguos contratos de gestión de servicios — por ejemplo, cuando se refiere a que ha de tratarse de una actividad que queda asumida por la Administración ${ }^{38}$ o a la continuidad del servicio o al derecho de utilizarlo de los particulares, etcétera-.

De hecho, que las mismas prestaciones pueden ser contratadas por una u otra vía se pone de relieve en las similares previsiones que se contienen en el régimen jurídico de una y otra figura; baste de ejemplo el citado art. 312 LCSP por lo que al contrato de servicios se refiere y las previsiones análogas contenidas en los arts. 284.2 o 288 de mismo cuerpo normativo en cuanto a la concesión de servicios.

puede consistir en explotar el servicio o en dicha explotación acompañada de un precio. Además, se matiza que la explotación ha de implicar la transferencia al concesionario del riesgo operacional a que se refiere la propia norma.

${ }^{37}$ El cual es definido en el art. 14.4 in fine del siguiente modo: «Se considerará que el concesionario asume un riesgo operacional cuando no esté garantizado que, en condiciones normales de funcionamiento, el mismo vaya a recuperar las inversiones realizadas ni a cubrir los costes en que hubiera incurrido como consecuencia de la explotación de las obras que sean objeto de la concesión. La parte de los riesgos transferidos al concesionario debe suponer una exposición real a las incertidumbres del mercado que implique que cualquier pérdida potencial estimada en que incurra el concesionario no es meramente nominal o desdeñable».

${ }_{38}$ Recuérdese que a ello se alude en la definición misma que el art. 15 hace de la concesión de servicios. 
Es más, el propio art. 312 se remite en cuanto a las causas de resolución del contrato de servicios no solo a las específicas de este tipo contractual establecidas en el art. 313, sino también a algunas de las señaladas en el art. 294, que se refiere a las propias del contrato de concesión de servicios.

Además, esta posible coincidencia de prestaciones también se pone de relieve a lo largo de todo el articulado de la norma cuando se hace referencia a los contratos de servicios especiales. $\mathrm{Y}$ es que a los mismos, previstos en el Anexo IV LCSP, se remiten en diversos preceptos de la LCSP, por ejemplo, los arts. 18.a), 22.c), 131, 134.6, 135.5, disposición adicional trigésima sexta, disposición adicional cuadragésima sexta y disposición adicional cuadragésima octava o el Anexo III, considerándolos de forma indistinta contratos de servicios o de concesión de servicios. Si bien del título de la nueva disposición adicional cuadragésima sexta pudiera desprenderse que sí hace algún tipo de distinción, la misma queda desvirtuada con el resto de menciones indicadas.

Y sin ninguna duda proviene de la propia confusión que al respecto se refleja en las Directivas de 2014, donde a la hora de referirse a los servicios que se incluyen y los que quedan excluidos se opta por previsiones similares, por lo que estriba la diferencia entre ambos en la mención al riesgo operacional $^{39}$.

Como se ha dicho ya, esta es una de las principales novedades de la nueva norma que aquí no se comparte, entendiendo que habría sido perfectamente posible trasponer las Directivas manteniendo nuestra tradición y definición misma de las categorías contractuales a que las mismas se refieren, más teniendo en cuenta cuál es el origen de esa normativa comunitaria, ajena por completo a nuestra tradición contractual desde esa perspectiva, pero también al concepto mismo de servicio público francés, que subyacía en el contrato de gestión de servicio público que hoy se ve sustituido por el contrato de concesión de servicios.

Si bien no es menos cierto que dicha distinción entre la concesión de servicios y el contrato de servicios atendiendo principalmente a la existencia o no del riesgo operacional ya se había venido aplicando en la práctica previamente a la trasposición de las nuevas Directivas por la LCSP y por claro efecto de las mismas e, incluso con anterioridad, de la jurisprudencia del Tribunal de Justicia de la Unión Europea ${ }^{40}$.

39 Vid. a este respecto los arts. 5, 10 o 19 de la Directiva 2014/23/UE y los arts. 2, 4 o 10, entre otros, de la Directiva 24/2014/UE, así como los Anexos IV y XIV, respectivamente.

${ }^{40}$ Por ejemplo, destaca la Sentencia de 10 de septiembre de 2009, asunto Wasser. 
A este respecto cabe mencionar diversos acuerdos ya del año 2013 del Tribunal Administrativo de Contratos Públicos de Aragón, que se hacen eco de esta postura jurisprudencial, recogida finalmente en las Directivas y en la LCSP, y donde se afirma con claridad que para poder hablar de contrato de gestión de servicio público, ahora de concesión de servicios, es condición sine qua non la transferencia del riesgo al contratista ${ }^{41}$.

En efecto, el criterio de diferenciación entre la concesión de servicios y el contrato de servicios empleado por la LCSP y que se basa en la transferencia o no del riesgo operacional ${ }^{42}$-que se aleja de nuestra tradición jurídica - proviene de la normativa europea y ya con anterioridad de la jurisprudencia del TJUE (valga de ejemplo la Sentencia de 10 de noviembre de 2011, asunto Norma-A y Dekom) ${ }^{43}$.

No obstante, si se pretendía seguir el criterio establecido en las Directivas y en la jurisprudencia del TJUE al respecto y apartarse con ello de nuestra tradición jurídica, debía al menos dotarse de una regulación adecuada al respecto al contrato de servicios, ya no solo por lo que se refiere a su inapropiada definición, sino porque, como bien advirtió el Consejo de Estado en su Dictamen al Anteproyecto de LCSP, con el hecho de que ahora se engloben dentro de esta figura servicios que pueden responder a servicios públicos y otros no, se generan importantes disfunciones al carecer de una regulación adecuada de esta cuestión, pues a salvo de las breves menciones contenidas en el art. 310, lo cierto es que este contrato carece de las previsiones necesarias para afrontar la contratación de aquellas prestaciones que impliquen un servicio público ${ }^{44}$.

${ }^{41}$ Vid. a este respecto, principalmente, los Acuerdos 52/2013, de 11 de septiembre, y 55/2013 del citado Tribunal de Recursos Contractuales.

${ }^{42}$ Tal y como la propia LCSP lo reconoce en su Preámbulo, en particular destaca el punto IV de la misma.

${ }^{43}$ Donde afirma que: «Si bien el modo de remuneración es uno de los elementos determinantes para la calificación de una concesión de servicios, de la jurisprudencia se desprende, además, que la concesión de servicios implica que el concesionario asuma el riesgo de explotación de los servicios de que se trate. La inexistencia de transmisión al prestador del riesgo relacionado con la prestación de los servicios indica que la operación en cuestión constituye un contrato público de servicios y no una concesión de servicios [vid., en particular, la Sentencia Privater Rettungsdienst und Krankentransport Stadler (TJCE 2011, 52), antes citada, apartado 26)]. Por consiguiente, es preciso comprobar si el prestador asume el riesgo de explotación del servicio en cuestión. Si bien este riesgo puede ser ciertamente muy limitado desde el primer momento, la calificación de concesión de servicios exige que la entidad adjudicadora transfiera al concesionario la totalidad o, al menos, una parte significativa del riesgo que corre [en este sentido vid., en particular, la Sentencia Privater Rettungsdienst und Krankentransport Stadler (TJCE 2011, 52), antes citada, apartado 29]».

${ }^{44}$ A este respecto, el Consejo de Estado llega a afirmar que las previsiones del art. 310 
Debe recordarse que, como ya se ha dicho, el nuevo texto normativo se aparta de la tradición de nuestro sistema, en que se separaban los contratos que implicaban la prestación de un servicio público - contrato de gestión de servicio público— de aquellos que no — contrato de servicios-, y opta por atender al criterio del riesgo operacional para diferenciar entre el contrato de servicios y el de concesión de servicios, por lo que a través de ambas figuras se pueden llevar a cabo tanto servicios públicos como aquellos que no lo son, lo que contribuye a distorsionar y complicar en igual medida el régimen de estos contratos.

\section{Algunos cambios destacados en los procedimientos de adjudicación}

Dentro de las muy variadas cuestiones que pueden ser analizadas dentro de lo que es la preparación y adjudicación de los contratos cabe destacar algunos temas relevantes.

Así, por ejemplo, a mi juicio, respecto a la solvencia de las empresas licitadoras, cuestión de gran relevancia y que puede resultar decisiva desde la perspectiva de la competencia, cabe indicar que la LCSP prevé expresamente la necesidad de que esté vinculada al objeto del contrato ${ }^{45}$-lo que puede en algún caso contribuir a dificultar la distinción con los criterios de adjudicación, como tantas veces ha sucedido con la expe-

—al menos en la versión remitida al mismo para informe - no resultan bastante «para hacer frente a las limitaciones y disfunciones que resultan de la apelación al contrato de servicios en la gestión de servicios públicos en que no se transfiera riesgo operacional. No se prevén en el contrato de servicios prescripciones (que sí se recogen para los servicios públicos objeto de concesión) como la inembargabilidad de los bienes en tanto que afectos al servicio público (art. 289.3); el secuestro o la intervención, en relación con el incumplimiento del contratista, atendida su vinculación con el servicio y el interés públicos (art. 291), o la inclusión entre las causas de resolución del contrato del rescate y la supresión del servicio por razones de interés público [art. 292.c) y d)] y, consecuentemente, los efectos a ellas vinculados (art. 293). Asimismo, ante la falta de previsión legal respecto del contrato de servicios, tampoco resultarán ejercitables por la Administración las potestades que el ordenamiento jurídico le confiere por tratarse de servicios públicos y que la legislación acota al contrato de gestión de los mismos. Entre las mismas cabe mencionar las potestades de ordenación y dirección del servicio público o de control sobre el mismo, todas ellas reconocidas en la normativa local».

${ }^{45}$ A este respecto cabe recordar que el TJUE ha venido distinguiendo entre los criterios de «selección cualitativa» y los criterios de «adjudicación», aclarando que los primeros tienen por finalidad la comprobación de la aptitud de los licitadores, mientras que los segundos están relacionados con el objeto del contrato y sirven para identificar a la mejor oferta. En relación con ello vid. la Sentencia de 12 de noviembre de 2009, asunto C-199/07, Comisión de las Comunidades Europeas contra República Helénica. 
riencia- ${ }^{46}$ y que sea proporcionada ${ }^{47}$. Además, no debe interpretarse de forma restrictiva, pues recuérdese que puede estar en tela de juicio la libre competencia y la igualdad de las empresas licitadoras ${ }^{48}$.

También la norma prevé la posibilidad de que se acredite la solvencia a través de medios externos a la propia empresa, sin que sea necesario siquiera que las empresas pertenezcan al mismo grupo; en línea, por tanto, con el concepto funcional de operador económico del Derecho comunitario ${ }^{49}$.

En cuanto a los contratistas, destaca también el tema de las prohibiciones para contratar, dentro de las que cabe destacar la ampliación de causas al respecto, especialmente en cuanto al conflicto de intereses. Además se ha obviado incluir la cláusula de clemencia, a pesar de estar prevista en la Directiva ${ }^{50}$.

Otra cuestión crucial de la nueva ley se refiere a la transparencia en la contratación ${ }^{51}$, destacando especialmente algunos aspectos ligados al procedimiento $^{52}$. Así, entre otras cuestiones a tener en cuenta en la materia cabe destacar la necesidad de motivación y justificación de la necesidad del contrato y del procedimiento ${ }^{53}$; la publicidad detallada de informa-

${ }^{46}$ Debe tenerse en cuenta además a este respecto, como bien recuerda T. MEDINA ARnÁIZ, «Comentario a los arts. 74 a 78 y 83 a 98», en J. M. MartíneZ FernándeZ, Contratación del Sector Público Local, 4. ${ }^{a}$ ed., Madrid, El Consultor de los Ayuntamientos, 2018, p. 487, que si bien es cierto que, con carácter general, la experiencia solo se había tenido en cuenta como criterio de admisión y no de adjudicación [por ejemplo, en las SSTS de 28 de abril de 2005 (RJ 2005\4702), de 14 de noviembre de 2006 (RJ 2006\9076) o de 21 de marzo de 2007 (RJ 2007\4043)], el TJUE en los últimos años ha venido aceptando que la misma pueda ser criterio de adjudicación si sirve para identificar la oferta económicamente más ventajosa y no la capacidad de los licitadores para ejecutar el contrato. Es el caso de la Sentencia de 26 de marzo de 2015, asunto C-601/13, Ambisig y Nersant.

47 Art. 74 LCSP.

48 Así, por ejemplo, como indicara el TJUE en su Sentencia de 18 de diciembre de 2007, asunto C-357/06, Frigerio Luigi, no puede exigirse una determinada forma jurídica.

49 Así, cabe recordar tanto el art. 75 LCSP como el art. 63 de la Directiva 2014/24/UE o las SSTJUE de octubre de 2013, asunto c-94/12, Swm Costruzioni 2 Spa, y de 2 de junio de 2016, asunto c-27/15, Pippo Pizzo.

${ }^{50}$ Como recuerda J. M. ${ }^{a}$ Gimeno FeLIÚ, «La nueva regulación de la contratación pública en España desde la óptica de la incorporación de las exigencias europeas: hacia un modelo estratégico, eficiente y transparente», en J. M. ${ }^{a}$ Gimeno Feliú (dir.), Estudio sistemático de la Ley de Contratos del Sector Público, Navarra, Thomson Reuters, 2018, p. 113.

${ }_{51} \mathrm{Al}$ respecto vid. J. M. MarTínez Fernández, Contratación Pública y transparencia..., op. cit.

52 Si bien debe tenerse en cuenta que transparencia en este ámbito no se vincula únicamente con publicidad, sino que, como bien ha explica el TJUE, no se es transparente si el pliego no es claro y un operador con diligencia media no es capaz de conocer con certeza las condiciones que se fijan en el mismo. Vid., a este respecto, la Sentencia de 16 de septiembre de 2013.

53 Art. 116.4 LCSP. A diferencia de la Directiva 2014/24/UE, que parte de la necesidad de motivación en caso de optar por un procedimiento de los especiales, es decir, licita- 
ción en el perfil del contratante, que tiene que estar alojado en la Plataforma de Contratación del Sector Público ${ }^{54}$ —obligación que se intensifica al ser el momento a tener en consideración para dar efectos a la publicación, así como por cuanto la falta de publicación es una causa de nulidad ${ }^{55}$ —; la publicidad de los contratos menores; el acceso a los pliegos y documentación por vía electrónica, o la publicidad y notificación de los modificados, susceptibles también de recurso especial.

Otra de las más importantes novedades de la LCSP es la obligación de división en lotes, que no de fraccionamiento del contrato, con la clara finalidad de beneficiar el acceso de las PYMES a los contratos, ya que la división en lotes - regla general que en caso contrario será necesario motivar- ${ }^{56}$ supone la posibilidad de licitar a pequeños y medianos empresarios cuyo ámbito de actividad se circunscribe a una parte del objeto contractual o a una localización territorial restringida ${ }^{57}$.

Si bien, con carácter excepcional, permite introducir limitaciones en dos direcciones: de un lado, restringir el número de lotes que pueden ser adjudicados al mismo licitador y, de otro, limitar los lotes a que puede presentarse cada empresa participante.

Por otro lado, y con anterioridad a entrar en los distintos tipos de procedimientos de adjudicación, cabe hacer referencia a las consultas preliminares del mercado, las cuales, a mi juicio, no estarán exentas de dificultades y ciertas polémicas. Y es que, como bien indica la norma, los órganos de contratación podrán realizar estudios de mercado y dirigir consultas a los operadores económicos que estuvieran activos en el mismo con la finalidad de preparar correctamente la licitación e informar a los citados operadores económicos acerca de sus planes y de los requisitos que exigirán para concurrir al procedimiento ${ }^{58}$.

ción con negociación, diálogo competitivo y asociación para la innovación, la LCSP no hace tal distinción, por lo que se deduce que tal motivación y justificación habrá de darse en todo caso, aunque bien es cierto que el art. 63.3 solo obliga a publicar la justificación en caso de optar por un procedimiento distinto al abierto o restringido.

${ }^{54}$ Art. 347 LCSP. En cuanto a este tema vid., por ejemplo, J. M. ${ }^{a}$ Gimeno Feliú, «El perfil del comprador europeo: una forma de innovar en contratación pública», RAP, núm. 192 (2013), pp. 381-400.

${ }_{55}$ Art. 39.2.c) LCSP.

56 En relación con supuestos en que no se realizó la división en lotes vid., por ejemplo, las Resoluciones del Tribunal de Recursos Contractuales de Andalucía 325/2016, 147/2017 y $203 / 2017$.

${ }^{57}$ A este respecto cabe recordar que la división puede atender a muy diversos criterios (por ejemplo, la naturaleza del objeto, el volumen, aspectos geográficos, funcionales, etc.).

${ }^{58}$ Art. 115 LCSP. 
La finalidad es clara y loable: conocer mejor el mercado y preparar de forma más adecuada la licitación, así como informar a los operadores económicos de los planes de contratación y de los requisitos que se exigirán ${ }^{59}$ —en fin, ganar en eficiencia- ${ }^{60}$, pero, no obstante, la dificultad es también considerable, pues todo ello habrá de hacerse sin menoscabo ni perjuicio de la libre competencia y del resto de principios que rigen la materia, es decir, sin que ello pueda suponer dar ventaja alguna a ciertos operadores, aunque, incluso, pueden haber sido consultados. A tal fin, y también con el propósito de que tal extremo pueda ser comprobado y controlado, debe darse publicad tanto previa, es decir, anunciar qué se va a consultar, como posterior, por lo que se refiere a los resultados de las consultas, a través del informe de actuaciones realizadas, que será objeto también de publicidad.

Por lo que se refiere a los diversos procedimientos de contratación, cabe destacar especialmente la supresión del procedimiento negociado sin publicidad por razón de la cuantía ${ }^{61}$, así como la creación de un procedimiento abierto simplificado y «super» simplificado, y del procedimiento de asociación para la innovación. Se mantiene, no obstante, el contrato menor, si bien con ciertas precauciones a que luego me referiré.

Además, se ha procedido a una importante uniformidad en el régimen jurídico aplicable a los poderes adjudicadores, sean o no Administración, al menos en cuanto a los contratos sujetos a regulación armonizada, por debajo de cuyos importes y por encima de los propios de los contratos menores, los segundos pueden optar por cualquiera de los procedimientos previstos en la sección 2. ${ }^{a}$ del capítulo I del título I del libro segundo de la LCSP, con excepción del negociado sin publicidad, que solo cabe en los supuestos excepcionales previstos en el art. $168^{62}$.

Por lo que se refiere al resto de entidades del sector público que no tienen la condición de poderes adjudicadores, así como los partidos políti-

59 Tal y como reconoce la propia normas en su Preámbulo.

${ }^{60}$ Pues, como ha indicado M. ${ }^{\text {a }}$ C. DE Guerrero MANSO, «Las consultas preliminares del mercado: una herramienta para mejorar la eficiencia en la contratación pública», en J. M. ${ }^{a}$ Gimeno Feliú (dir.), Estudio sistemático de la Ley de Contratos del Sector Público, Navarra, Thomson Reuters, 2018, p. 1047, la falta de eficiencia en la contratación viene en gran medida de la ausencia de una adecuada transparencia y publicidad previa, de tal modo que los operadores económicos tengan una adecuada información.

${ }^{61}$ Algo que ya se había hecho a través del Decreto-ley de Cataluña 3/2016, de 31 de mayo.

${ }_{62} \mathrm{Tal}$ y como prescribe el art. 318. 
cos, los sindicatos, asociaciones profesionales, etc., se regirán por las instrucciones que a tales efectos han de aprobar ${ }^{63}$.

Partiendo de estas cuestiones previas, es preciso exponer, brevemente, las principales novedades que en los tipos de procedimientos de contratación se han introducido por la LCSP.

En primer lugar, en cuanto al procedimiento abierto, lo cierto es que las novedades no derivan de la Directiva, que, por otro lado, salvo la reducción de plazos, no procedió a grandes cambios, sino que se debe a la necesidad de compensar la desaparición del procedimiento negociado sin publicidad por razón de la cuantía, de tal modo que, en cierto modo, se suple dicho vacío con la creación de un procedimiento abierto simplificado $^{64}$, al que se añade, en la tramitación parlamentaria, una «tramitación especial», lo que se ha dado en llamar por la doctrina un procedimiento «simplificadísimo»o «super» simplificado ${ }^{65}$.

En segundo lugar, dentro de las novedades cabe destacar el reforzamiento que se da a la publicidad en el perfil del contratante ${ }^{66}$, que pasa a ser el referente temporal, así como la posibilidad de recabar informes para la valoración de proposiciones no solo de carácter técnico, sino también para la verificación de las consideraciones sociales y ambientales. Si bien coincido con alguna autora que considera que la opción introducida en la tramitación parlamentaria respecto a la viabilidad de recoger la opinión de organizaciones sociales, vecinales, sindicales y otros grupos representativos de intereses sociales con la finalidad de que la sociedad civil afectada por los contratos pueda participar hubiera sido más adecuada canalizarla de otro modo o en otro momento, pues la valoración de las ofertas ha de ser de carácter técnico y objetivo ${ }^{67}$.

${ }^{63}$ Las cuales, como bien recuerda el art. 321, han de regular los procedimientos de contratación de forma que quede garantizada la efectividad de los principios de publicidad, concurrencia, transparencia, confidencialidad, igualdad y no discriminación, así como que los contratos se adjudiquen a quienes presenten la mejor oferta, de conformidad con lo dispuesto en el art. 145.

${ }^{64}$ Tal y como reconoce el propio Preámbulo de la LCSP.

${ }^{65}$ Es el caso de I. Gallego Córcoles, «Los procedimientos abiertos, restringido, licitación con negociación, negociado sin publicidad y diálogo competitivo», en J. M. ${ }^{a}$ GIMENO Feliú (dir.), Estudio sistemático de la Ley de Contratos del Sector Público, Navarra, Thomson Reuters, 2018, p. 1081.

${ }^{66}$ A este respecto vid., por ejemplo, I. GALLEGo CórCOLES, «La utilización del procedimiento negociado sin publicidad por razones de exclusividad técnica», Contratación Administrativa Práctica, núm. 149 (2017).

${ }^{67}$ I. Gallego CórColes, «Los procedimientos abiertos...», op. cit., p. 1087. 
Pero, sin duda, la gran novedad es el procedimiento abierto simplificado, tomado en gran medida de algunas normas autonómicas que ya lo habían previsto ${ }^{68}$ y con el que se busca que la selección del contratista pueda resultar ágil sin merma de las garantías de publicidad y concurrencia.

Precisamente por esta razón, está pensado fundamentalmente para supuestos que no sean de gran complejidad, en los que será más adecuado acudir a otros procedimientos (por ejemplo, la licitación con negociación). De ahí también que no solo la ley exija que se justifique por cuál se ha optado, sino la importancia de que quien gestiona el tema de la contratación conozca bien los diversos resortes de la misma. No en vano se viene exigiendo desde la Unión Europea una importante profesionalización al respecto ${ }^{69}$.

Este procedimiento, en el que se reducen los plazos y los trámites, aunque resulta difícil que pueda sustanciarse en un mes como dice el Preámbulo de la norma, solo cabe para contratos de obras inferiores a dos millones de euros y servicios y suministros de menos de 100.000. De tal modo que se excluye su empleo de las concesiones de obras y servicios, muy probablemente por su mayor complejidad.

De igual modo, y aunque ha sido debatido ${ }^{70}$, solo cabe recurrir a este procedimiento cuando los criterios con juicio de valor no superen el 25 por 100 de la puntuación, pudiendo alcanzar el 45 por 100 para los servicios de ingeniería o arquitectura.

Los trámites pueden resumirse en los siguientes: la publicación del anuncio de licitación en el perfil de contratante; la necesidad de que el acceso a la documentación se haga electrónicamente ${ }^{71}$; la presentación de proposiciones se realizará en un plazo de quince días, veinte si son obras, y el licitador, en principio, y siempre que ello no restrinja la competen-

${ }^{68}$ Es el caso de la Ley de Aragón 3/2011, de 24 de febrero, o el Decreto-ley de Cataluña 3/2016, de 31 de mayo.

${ }^{69}$ Recomendación (UE) 2017/1805 de la Comisión, de 3 de octubre de 2017, sobre la profesionalización de la contratación pública. Construir una arquitectura para la profesionalización de la contratación pública.

70 Así, cabe mencionar en contra a F. BlAnCo LóPEZ, «Propuesta de regulación legal del procedimiento abierto simplificado», Observatorio de Contratación Pública, 4 de enero de 2016, disponible en http://www.obcp.es/index.php/mod.opiniones/mem.detalle/id.217/relcategoria.121/relmenu.3/chk.511d2896c061bb5c8ec44e0a94272051 (consultado el 6 de abril de 2018). Si bien es cierto que la medida responde a que la mayor agilidad se dará más fácilmente cuando la valoración sea más sencilla, en línea con lo dicho por la Junta Consultiva de Contratación Administrativa de Aragón en su informe 15/2011, de 8 de junio.

${ }^{71}$ Medida que perderá utilidad en el momento que se generalice la contratación electrónica, como, por otro lado, prevé la propia norma [art. 63.3.a)]. 
cia, deberá estar inscrito en el Registro Oficial de Licitadores y Empresas Clasificadas del Sector Público ${ }^{72}$; se excluirá la posibilidad de que se preste garantía provisional; las proposiciones solo se podrán presentar en el Registro indicado en el anuncio de licitación y la Mesa de Contratación deberá, en la misma sesión, y salvo que se trate de un caso de baja anor$\mathrm{mal}^{73}$, clasificar y evaluar las ofertas, realizar la propuesta de adjudicación, comprobar los requisitos de capacidad y solvencia, y requerir para la constitución de la garantía definitiva, si bien no debe perderse de vista que la valoración de la oferta técnica se atribuye a los servicios técnicos - lo que introduce confusión e incluso resta utilidad a la Mesa de Contratación- ${ }^{74}$.

Como ya se ha indicado, durante el debate parlamentario se ha incluido un procedimiento abierto «simplificadísimo» $\mathrm{o}$ «super» simplificado ${ }^{75}$ para obras inferiores a 80.000 euros y suministros y servicios de menos de 35.000 y que no sean de carácter intelectual ${ }^{76}$, es decir, para contratos de baja cuantía y escasa complejidad, que trata de reducir la utilización, excesiva hasta el momento en nuestro país, del contrato menor ${ }^{77}$, aunque otra cuestión distinta será que se consiga dicho objetivo, máxime cuando no se trata de un procedimiento obligatorio y sigue existiendo — aunque en los términos más restrictivos a que luego me referiré- dicho contrato.

En el mismo se reducen aún más los plazos ${ }^{78}$, se exime a los licitadores de acreditar la solvencia, se presentará un único sobre o archivo electróni-

${ }^{72}$ Lo que resulta en sí mismo complicado, de tal modo que habrá que entender, como sugiere la doctrina, que no cabrá exigir la inscripción cuando no haya empresas en dicho registro para ese tipo de contrato o se reduzcan de tal modo que la competencia se vea distorsionada. Vid. I. GALLEGo CórColes, «Los procedimientos abiertos...», op. cit., p. 1097.

73 Además, en cuanto a esta cuestión, solo se pide justificación frente a la consideración de oferta anormalmente baja al licitador que haya obtenido mayor puntuación, lo que, en su caso, puede resultar contraproducente, si finalmente no la justifica.

${ }_{74}$ Tal y como ha advertido, entre otros, M. Ruiz Daimiel, «Tres errores en el nuevo procedimiento abierto simplificado», Observatorio de Contratación Pública, 24 de abril de 2017, disponible en http://www.obcp.es/index.php/mod.opiniones/mem.detalle/id.288/relcategoria.208/relmenu.3/chk.8901b68b9db71930b37bf38d779c1aef (consultado el 6 de abril de 2018).

75 Aunque en la ley se denomina tramitación sumaria del procedimiento abierto simplificado.

${ }^{76}$ Lo que resulta lógico, dado que no podrán emplearse criterios de valoración de apreciación subjetiva.

77 Tal y como advierte, entre otros, J. M. a Gimeno Feliú, «Transparencia activa e integridad: posibilidades y límites actuales en la legislación de contratos públicos», en J. M. ${ }^{a}$ Gimeno Feliú y M. A. Bernal Blay (coords.), Observatorio de Contratación Pública 2013, Navarra, Thomson Reuters, 2014, p. 43, quien sostiene que se trata de uno de los más graves problemas de la contratación pública en España.

${ }_{78}$ Así, el plazo de presentación de proposiciones no podrá ser inferior a diez días, aun- 
co — dado que solo cabe la valoración mediante fórmulas—, no se requiere garantía definitiva y la formalización podrá hacerse mediante firma de aceptación por el contratista de la resolución de adjudicación.

También cabe destacar, dentro de las novedades en los procedimientos, la potenciación de la negociación y la creación del procedimiento de asociación para la innovación, además de lo que se dirá seguidamente respecto a los contratos menores.

Otra de las principales novedades introducidas en materia de adjudicación es la creación de un nuevo procedimiento, la asociación para la innovación ${ }^{79}$, en línea con la potenciación de esta última que hace la nueva ley.

En puridad, el objeto del mismo es el acuerdo previo a uno o varios contratos posteriores, dado que de que lo se trata es de «asociarse» para investigar y crear obras, servicios o productos que no existen en el mercado y que serán, en su caso, los que se adquirirán después. En fin, se trata de un acuerdo de colaboración entre el órgano de contratación y uno o varios empresarios con la finalidad de investigación y desarrollo respecto de obras, servicios y productos innovadores y su ulterior adquisición cuando los productos existentes en el mercado no satisfacen las necesidades.

En esa selección que daría lugar al acuerdo se destaca que en los Pliegos de Cláusulas Administrativas Particulares (en adelante, PCAP) deberán contenerse aspectos relevantes como los derechos de propiedad intelectual o industrial; la estructura de la asociación; las retribuciones, duración, número de fases, objetivos y criterios de verificación, así como la posible salida si no se cumplen los términos de la adjudicación y criterios de negociación.

Una vez finalizadas las fases de investigación y desarrollo y analizado el nivel de rendimiento y coste, será cuando se resolverá sobre la adquisición de obras, servicios o suministros resultantes. Sin que puedan superarse los cuatro años en caso de prestaciones sucesivas y teniendo que atender en la adjudicación a la mejor relación calidad-precio ${ }^{80}$.

que si se trata de compra corriente de bienes disponibles en el mercado el plazo podrá reducirse a cinco.

79 Arts. 117 a 182 LCSP.

${ }^{80}$ En general sobre este procedimiento vid., por ejemplo, M. ${ }^{a}$ Hernando Rydings, «El procedimiento de asociación para la innovación», en J. M. ${ }^{a}$ Gimeno Feliú (dir.), Estudio sistemático de la Ley de Contratos del Sector Público, Navarra, Thomson Reuters, 2018, pp. 1147 y ss., y J. A. TARDío PATO, «La "asociación para la innovación”: contrato, procedimiento de adjudicación y libre competencia», REDA, núm. 181 (2016), pp. 267-295. 
Para concluir con las principales novedades en materia de procedimientos de adjudicación cabe referirse a los contratos menores ${ }^{81}$, tema siempre debatido. La nueva regulación ha dado lugar ya a diversos pronunciamientos de la Junta Consultiva de Contratación Administrativa (en adelante, JCCA) del Estado y de la JCCA de Aragón, que han precisado los términos en que debe ser interpretado el polémico art. 118 LCSP.

En dicho artículo lo que se establece es una importante cautela para evitar el fraccionamiento fraudulento de contratos con la finalidad de eludir los procedimientos de contratación. Esta es la idea que subyace a las previsiones contenidas en la norma.

De este modo, lo que impide el precepto en cuestión es que se lleven a cabo contratos similares con el mismo contratista por importe superior a 40.000 euros, si se trata de obras, y 15.000, si son servicios o suministros.

Además, se exige que el expediente contenga el informe del órgano de contratación motivando la necesidad del contrato, así como la aprobación del gasto y la factura. A lo que debe añadirse, en el caso de las obras, el presupuesto de las mismas.

Pero quizá lo más relevante o novedoso es que se exija que en el expediente se justifique que no se está alterando el objeto del contrato para evitar la aplicación de las reglas generales de contratación, y que el contratista no ha suscrito más contratos menores que, individual o conjuntamente, superen la cifra indicada.

Como ya se ha adelantado, varias son las dudas que el art. 118 ha suscitado. No obstante, a dar respuesta a estas se han dedicado varios informes de la JCCA del Estado ${ }^{82}$, cuya doctrina puede resumirse en las siguientes conclusiones.

De un lado, que se trata de evitar la alteración del objeto, es decir, el objetivo es frenar la conducta defraudatoria, de tal modo que caben, por tanto, varios contratos menores con el mismo contratista si son cualitativamente diferentes o cuando el contrato, aun siendo similar, haya transcurrido más de un año desde la incorporación de la factura.

El plazo de un año se fija en el art. 29 LCSP, y para el cómputo del mismo, como se ha indicado, lo determinante es la perfección del primer contrato menor considerado.

${ }^{81}$ A este respecto vid., entre otros, J. M. MARTínEZ FeRnÁndEZ, «La imprescindible necesidad de anticipación para afrontar las limitaciones a los contratos menores que impone la nueva Ley de Contratos del Sector Público», El Consultor de los Ayuntamientos, núm. 20 (2017), p. 2425.

${ }^{82}$ Informes 41/2017, 42/2017 y 5/2018. 
De otro lado, el informe de necesidad ha de ser firmado por el titular del órgano de contratación.

Cabe destacar, de igual modo, el Informe de la JCCA de Aragón 3/2018, de 13 de febrero, a mi juicio más preciso, y del que cabe concluir que la limitación se establece por órgano de contratación y no por entidad, así como por tipo de contrato, que también se incluyen los tramitados por anticipo de caja inferior a 5.000 euros y que ha de tomarse como referencia la anualidad presupuestaria.

Finalmente cabe recordar que la propia norma prevé tres supuestos especiales de contratos menores. Me refiero a los contratos de servicios sanitarios de urgencia de importe inferior a 30.000 euros (art. 131.4), las actividades docentes del art. 310 y la suscripción de publicaciones y acceso a bases de datos hasta el importe de la regulación armonizada ${ }^{83}$.

\section{4. ¿Qué cuestiones será imprescindible tomar en consideración a la hora de confeccionar y aplicar los criterios de adjudicación?}

A mi juicio, por lo que a la adjudicación se refiere cabe destacar la importante reforma en materia de criterios aplicables, los cuales se vinculan a la lógica de la calidad-precio, además de una apuesta más decidida por la inclusión de criterios sociales y medioambientales y el papel del coste de ciclo de vida del producto.

Muy brevemente pueden señalarse las siguientes cuestiones fundamentales a tener en cuenta.

En primer lugar, que la regla general es la pluralidad de criterios basados en el principio de mejor relación calidad-precio, que no se habla de precio, sino de coste o rentabilidad, y se ponen en valor los servicios intelectuales.

En segundo lugar, los criterios han de estar vinculados al objeto del contrato — si bien cabe, como ha dicho el TJUE respecto de los criterios sociales, una relación indirecta- ${ }^{84}$; ser formulados de forma objetiva, con pleno respeto a los principios de igualdad, no discriminación, transparencia y proporcionalidad, sin que puedan conferir al órgano de contratación una libertad de decisión ilimitada, y deberán garantizar la posibilidad de que las ofertas sean evaluadas en condiciones de competencia efectiva.

\footnotetext{
${ }^{83}$ A los que se refiere la disposición adicional novena de la LCSP.

${ }^{84}$ Recuérdese, entre otras, la Sentencia del TJUE de 10 de mayo de 2012, asunto c-368/10, sobre la posibilidad de introducir el comercio justo.
} 
Se distingue entre criterios relacionados con el coste (mejor coste-eficacia) y criterios cualitativos (mejor relación calidad-precio). Cabe excepcionalmente, y siempre que se justifique debidamente, la utilización de un único criterio, que será el de los costes, es decir, la mejor relación coste-eficacia. Además, las mejoras, que se definen como prestaciones adicionales, no podrán superar el 2,5 por 100 .

Todo ello hace que de nuevo sea imprescindible la profesionalización, pues tanto la confección del baremo atendiendo a todo lo dicho como la valoración adquieren gran complejidad. Lo que se pone de manifiesto por la propia norma cuando, por ejemplo, prevé que el plazo máximo para la adjudicación desde la apertura de las proposiciones será de dos meses ${ }^{85}$ en aquellos casos en que haya una pluralidad de criterios o utilizándose un único criterio sea el del menor coste del ciclo de vida ${ }^{86}$.

\section{Algunas cuestiones a destacar en la regulación del cumplimiento y extinción de los contratos}

Siguiendo el esquema básico de las cuatro fases de todo contrato, es menester ahora hacer una brevísima referencia al cumplimiento y extinción. La primera novedad destacable es que por primera vez las Directivas de las que trae causa la LCSP entran en cuestiones de este tipo (por ejemplo, por lo que se refiere a la modificación de los contratos y alguna causa de resolución).

Como es bien sabido, hasta ahora el Derecho comunitario se había limitado a las dos primeras fases, dado que su objetivo no era otro que salvaguardar los principios en la preparación y adjudicación de los contratos. Sin embargo, no es menos cierto que algunas cuestiones propias de las últimas fases pueden incidir también en las primeras (baste de ejemplo el tema del ius variandi), pues en ciertos supuestos las modificaciones contractuales pueden implicar cambios que hubieran podido alterar la adjudicación de haberse conocido o que, incluso, pueden realmente requerir una nueva licitación.

En línea con lo anterior, también es preciso destacar que algunas de estas cuestiones reguladas en la ley con carácter general para los contratos administrativos también son de aplicación a los contratos privados de

\footnotetext{
${ }^{85}$ Art. 158.2.

${ }^{86}$ Sobre la complejidad de valorar este criterio ya se ha manifestado la doctrina, por ejemplo, R. Delgado FernándeZ, «El cálculo del coste de ciclo de vida en la contratación administrativa», Gabilex, núm. 7 (2016), pp. 116-152.
} 
las Administraciones Públicas y a los contratos de los poderes adjudicadores, aunque no sean Administración. En particular, son de aplicación las condiciones especiales de ejecución; las obligaciones sociales, laborales y medioambientales; determinados supuestos de modificación, cesión y subcontratación; la causa de resolución del art. 211.i), y en las concesiones, las causas de los arts. 279 y $294^{87}$.

Todo ello ha provocado igualmente una importante ampliación de la competencia de la jurisdicción contencioso-administrativa, dando un paso más hacia la unidad de jurisdicción y prescindiendo del criterio subjetivo, es decir, de que esté presente una Administración Pública, ya que incluso conoce de la preparación y adjudicación de los contratos de las entidades del sector público, aunque no sean poder adjudicador ${ }^{88}$.

Otro aspecto destacado dentro del cumplimiento de la prestación se refiere a las condiciones especiales de ejecución, que si bien ya estaban previstas en la normativa anterior, ahora pasa a ser obligatorio introducir - al menos una-, fijando la norma los objetivos que en caso de las de tipo medioambiental y social han de perseguir ${ }^{89}$, y exigiendo que estén vincula-

${ }^{87}$ De conformidad con lo establecido en el art. 319 LCSP, si bien choca que no precise si esa aplicación es solo para los contratos sometidos a regulación armonizada o no, cuando, por el contrario, al referirse a ciertos aspectos del cumplimiento y extinción que son de aplicación a los contratos privados de las Administraciones lo circunscribe a aquellos que superen las cuantías de las Directivas, tal y como matiza el art. 26.2 de la misma norma.

${ }^{88} \mathrm{Vid}$. a este respecto el art. 27 LCSP.

${ }^{89}$ Así, en particular, el art. 202 precisa que: «Se podrán establecer, entre otras, consideraciones de tipo medioambiental que persigan: la reducción de las emisiones de gases de efecto invernadero, contribuyéndose así a dar cumplimiento al objetivo que establece el art. 88 de la Ley 2/2011, de 4 de marzo, de Economía Sostenible; el mantenimiento o mejora de los valores medioambientales que puedan verse afectados por la ejecución del contrato; una gestión más sostenible del agua; el fomento del uso de las energías renovables; la promoción del reciclado de productos y el uso de envases reutilizables, o el impulso de la entrega de productos a granel y la producción ecológica. Las consideraciones de tipo social o relativas al empleo podrán introducirse, entre otras, con alguna de las siguientes finalidades: hacer efectivos los derechos reconocidos en la Convención de las Naciones Unidas sobre los derechos de las personas con discapacidad; contratar un número de personas con discapacidad superior al que exige la legislación nacional; promover el empleo de personas con especiales dificultades de inserción en el mercado laboral, en particular de las personas con discapacidad o en situación o riesgo de exclusión social a través de empresas de inserción; eliminar las desigualdades entre el hombre y la mujer en dicho mercado, favoreciendo la aplicación de medidas que fomenten la igualdad entre mujeres y hombres en el trabajo; favorecer la mayor participación de la mujer en el mercado laboral y la conciliación del trabajo y la vida familiar; combatir el paro, en particular el juvenil, el que afecta a las mujeres y el de larga duración; favorecer la formación en el lugar de trabajo; garantizar la seguridad y la protección de la salud en el lugar de trabajo y el cumplimiento de los convenios colectivos sectoriales y territoriales aplicables; medidas para prevenir la siniestralidad laboral; otras finalidades que se establezcan con referencia a la estrategia coordinada para el empleo 
das al objeto del contrato y que las cumplan todos los subcontratistas que participen en la ejecución del contrato.

$\mathrm{Su}$ incumplimiento puede conllevar la imposición de penalidades e, incluso, si se configuran como obligaciones contractuales esenciales, podría derivar en la resolución del contrato y, en caso de ser infracción grave, incluso suponer incurrir en prohibición para contratar.

Las principales novedades en materia de modificación de los contratos, a mi juicio, provienen no tanto de los supuestos en que cabe la misma - ya que a este respecto continúa distinguiéndose entre las modificaciones previstas en los pliegos y aquellas que no lo han sido-, sino del ámbito de aplicación de este régimen y en la vías de control ${ }^{90}$.

Aunque cabe destacar la previsión del art. 205.2.c), por cuanto permite las modificaciones no sustanciales, justificando especialmente la necesidad de las mismas e indicando las razones por las que esas prestaciones no se incluyeron en el contrato inicial, sería fijar mayores límites al respecto. Habrá que ver si no se convierte en la práctica en una importante vía de escape para llevar a cabo modificaciones, por más que estas no sean sustanciales.

$\mathrm{Y}$ es que, como ya se ha dicho, de un lado, algunas de estas cuestiones se aplican también a los contratos privados de las Administraciones Públicas y a los contratos de los poderes adjudicadores no Administración, y de otro, las modificaciones han de ser publicadas y son susceptibles de recurso especial cuando esté basado en el incumplimiento de lo establecido en los arts. 204 y 205 por entender que la modificación debió ser objeto de una nueva adjudicación ${ }^{91}$.

Finalmente, cabe hacer una brevísima referencia a las causas de resolución del contrato ${ }^{92}$, respecto de las cuales la principal novedad se cierne

definida en el art. 145 del Tratado de Funcionamiento de la Unión Europea, o garantizar el respeto a los derechos laborales básicos a lo largo de la cadena de producción mediante la exigencia del cumplimiento de las convenciones fundamentales de la Organización Internacional del Trabajo, incluidas aquellas consideraciones que busquen favorecer a los pequeños productores de países en desarrollo con los que se mantienen relaciones comerciales que les son favorables, tales como el pago de un precio mínimo y una prima a los productores o una mayor transparencia y trazabilidad de toda la cadena comercial».

${ }^{90}$ En cuanto a las principales novedades en materia de modificación cabe remitirse a J. M. ${ }^{a}$ BAÑo LEÓN, «El "modificado" de los contratos», en J. M. ${ }^{a}$ Gimeno Feliú (dir.), Estudio sistemático de la Ley de Contratos del Sector Público, Navarra, Thomson Reuters, 2018, pp. 1345 y ss.

${ }_{91}$ Art. 44.2.d) LCSP.

92 A este respecto ya he tenido ocasión de manifestarme en E. M. ${ }^{a}$ Menéndez SebasTIÁN, «La extinción del contrato: la resolución», en E. GAMERO CASADO e I. GaLLEGo CóRcoles (dirs.), Tratado de Contratos del Sector Público, vol. 3, Valencia, Tirant lo Blanch, 2018. 
sobre la introducción de una nueva causa [me refiero a la establecida en el art. 211.1.i) LCSP] que se introdujo en fase de enmiendas en el Congreso de los Diputados.

Ciertamente, a mi juicio, esta nueva causa, que se produce cuando se da el impago, durante la ejecución del contrato, de los salarios por parte del contratista a los trabajadores que estuvieran participando en la misma, o el incumplimiento de las condiciones establecidas en los convenios colectivos en vigor para estos trabajadores también durante la ejecución del contrato, enlaza —o más bien se debe- a las imposiciones de las Directivas 2014/23/UE y 2014/224/UE y, en particular, a la obligación de velar por parte de los Estados miembros de que los contratistas cumplan con la normativa laboral —medioambiental y social- ${ }^{93}$, en línea con lo que se ha dado en llamar «contratación social» ${ }^{94}$.

Se trata de una nueva causa de resolución muy interesante y que, en cierta medida, introduce importantes cambios; así, por ejemplo, por lo que se refiere a la legitimación para pedir la resolución en esos casos, la misma ya no está en manos de la Administración o el contratista, sino de los representantes de los trabajadores de este, como ya se ha advertido.

También cabe destacar que, muy acertadamente, la LCSP circunscribe el supuesto a que dichos incumplimientos sean en relación con los trabajadores que están participando en la ejecución del contrato, como no podría ser de otro modo. $\mathrm{Y}$ es que, de igual manera que sucede con las condiciones especiales de ejecución, estas deben tener vinculación con el objeto del contrato.

A mi juicio, debe valorarse muy positivamente la inclusión de esta nueva causa de resolución, si bien podría haberse extendido a otros incumplimientos (por ejemplo, en cuanto a los derechos de conciliación de los trabajadores $)^{95}$.

${ }^{3}$ Debe recordarse que incluso dichas normas comunitarias prevén la posibilidad de no adjudicar el contrato a la oferta económicamente más ventajosa si el licitador no cumple con las obligaciones medioambientales, sociales o laborales.

${ }^{4}$ A este respecto vid. lo dicho ya en E. M. ${ }^{a}$ Menéndez Sebastián, «La contratación social...», op. cit., pp. 3403-3428.

${ }_{95}$ Puesto que precisamente la utilización de la contratación como mecanismo de fomento, o, en este caso, de elemento disuasorio, para las empresas en el ámbito de la igualdad de género y las diversas cuestiones conexas con la misma, es objeto de atención de la propia Ley Orgánica 3/2007, de 22 de marzo, de Igualdad. A este respecto vid. lo dicho en E. M. ${ }^{a}$ MenÉndez SebASTIÁn, La Administración promotora de la igualdad de género, Valencia, Tirant lo Blanch, 2012. 


\section{La extensión del recurso especial en materia de contratos como mecanismo de control}

Sin duda, la labor que han venido desarrollando los tribunales de recursos contractuales ha dado sus frutos y prueba de su buen hacer es la ampliación que la nueva LCSP ha hecho respecto del ámbito de aplicación del recurso especial, que constituye un mecanismo de control de gran eficacia ${ }^{96}$ y una medida de «anticorrupción» importante ${ }^{97}$.

Así, en esa idea de integridad que vertebra la nueva norma no podía faltar un importante refuerzo de los controles, siendo uno de ellos el recurso especial. Esta ampliación se ha dado tanto desde la perspectiva del objeto, en cuanto a los contratos que son susceptibles del mismo, que no se circunscribe a los sujetos a regulación armonizada, sino que abarca los contratos de obras que superen los tres millones de euros, los de servicios y suministros por encima de los 100.000 euros, las concesiones de obras y servicios de más de tres millones, los contratos administrativos especiales por importe superior a 100.000 euros, así como los acuerdos marco o sistemas dinámicos de adquisición y los contratos subvencionados, como respecto a cualquier poder adjudicador, sea o no Administración, y sin necesidad de que se trate de contratos sujetos a regulación armonizada.

Sin olvidar que también son susceptibles de este recurso las modificaciones del contrato por entender que exige una nueva adjudicación ${ }^{98}$, la formalización de encargos a medios propios o los acuerdos de rescate de las concesiones ${ }^{99}$.

${ }^{6} \mathrm{Y}$ es que, como bien ha reconocido el TJUE en su Sentencia de 23 de julio de 2014, asunto C-203/14, en estos tribunales se dan las notas de carácter contradictorio del procedimiento, independencia y carácter obligatorio de su jurisdicción que justifican su consideración como órgano jurisdiccional en el sentido del art. 267 TFUE, es decir, que se les permite plantear una cuestión prejudicial.

${ }_{97}$ Como bien ha indicado E. Hernández SALguero, «El nuevo objeto del recurso especial en materia de contratación», en J. M. ${ }^{a}$ Gimeno Feliú (dir.), Estudio sistemático de la Ley de Contratos del Sector Público, Navarra, Thomson Reuters, 2018, p. 641.

98 Vid. a este respecto, entre otras, las SSTJUE de 29 de abril de 2004, asunto C-496/99, Succhi de Fruta; de 19 de junio de 2008, asunto C-454/06, Pressetex, o la STGUE de 31 de enero de 2013, asunto T-235/11, de las que traen causas las nuevas previsiones legales.

99 Si bien debe recordarse que la LCSP, en cuanto a los requisitos para el rescate de las concesiones (arts. 227 y 292), exige que la misma se deba a razones de interés público y que la gestión directa resulte más eficaz y eficiente que la concesión, lo que implica que los tribunales de recursos contractuales tengan que pronunciarse sobre aspectos más económicos que jurídicos por lo que a la segunda cuestión se refiere. 
De otro lado, esta expansión también se ha realizado desde el punto de vista de los legitimados para interponerlo, al referirse a toda persona física o jurídica cuyos derechos o intereses legítimos, individuales o colectivos, se hayan visto perjudicados o puedan resultar afectados de manera directa o indirecta por las decisiones objeto del recurso, así como a las organizaciones sindicales - para el supuesto de incumplimiento de las obligaciones sociales o laborales-y, en todo caso, a la organización empresarial sectorial representativa de los intereses afectados.

Dentro de las principales novedades en lo que se refiere al procedimiento $^{100}$ destaca la mayor precisión respecto al cómputo de plazo, que además puede variar en función de las causas, dado que - recuérdesela acción de nulidad específica que se preveía en la normativa anterior se ha suprimido ${ }^{101}$.

También cabe mencionar la referencia expresa a que la estimación de un recurso contra pliegos conlleva la nulidad de los actos del expediente de contratación, así como que, en caso de estimación del recurso, el órgano de contratación deberá dar conocimiento al Tribunal de las actuaciones para cumplir la resolución; que podrá fijarse en indemnización de daños y perjuicios a cualquier interesado.

Destaca también la ampliación de las multas por mala fe y perjuicio hasta 30.000 euros y la previsión respecto a que cabe la rectificación de errores materiales, de oficio o a instancia del interesado, pero no así revisión de oficio de las resoluciones de estos tribunales.

Cabe concluir, no obstante, haciendo referencia a una cuestión cuanto menos dudosa, como es el carácter potestativo del recurso, ya que en la redacción inicial del proyecto de ley se había establecido como obligatorio algo que, a mi juicio, era más positivo, por cuanto puede darse la circunstancia de que una misma licitación haya sido impugnada por algún intere-

100 Por lo que se refiere a algunas disfunciones que el mismo presentaba en su regulación originaria, aunque muchas de ellas ya habían sido corregidas por el Real Decreto $814 / 2015$, de 11 de noviembre, por el que se aprueba el Reglamento de los procedimientos especiales de revisión de decisiones en materia contractual y de organización del Tribunal Administrativo Central de Recursos Contractuales, cabe remitirse a lo dicho en E. M. ${ }^{a}$ Menéndez Sebastián, «Virtualidad práctica del recurso especial en materia de contratación pública: una figura inacabada», RAP, núm. 188 (2012), pp. 365-391.

${ }^{101}$ A mi juicio, dicha supresión es algo positivo. No obstante, la diferencia de plazo, especialmente la posibilidad de que este se amplíe hasta los seis meses, podría ser un tanto contradictorio con la celeridad del propio recurso, que, sin duda, es una de sus fortalezas, como bien ha dicho M. J. SAntiago Fernández, «Procedimiento del recurso especial en materia de contratación», en J. M. ${ }^{a}$ Gimeno Feliú (dir.), Estudio sistemático de la Ley de Contratos del Sector Público, Navarra, Thomson Reuters, 2018, p. 686. 
sado en vía administrativa - a través de este recurso-, por un lado, y en la jurisdicción contencioso-administrativa, por otro.

No obstante, sí resulta plausible que se haya configurado expresamente como gratuito, por cuanto alguna Comunidad Autónoma ${ }^{102}$ había establecido lo contrario, de tal modo que dicha previsión ha devenido ilegal.

\section{REFLEXIÓN FINAL}

Tras haber expuesto muy brevemente las principales novedades que se han introducido con la nueva LCSP, que si bien parte en muchas cuestiones del texto normativo anterior, a mi juicio, sí ha dado un importante giro en algunos aspectos ${ }^{103}$, cabe concluir, en cierto modo como se comenzó, que se abre una oportunidad importante para que las Administraciones orienten de forma más eficaz e íntegra su modo de contratación.

La norma ofrece a este respecto mimbres para ello; cuestión distinta es que no sea una tarea sencilla. Pero, a mi juicio, de lo que no cabe duda es que sin una apuesta decidida en esta línea, con los esfuerzos que ello conlleva, los elogiables objetivos de la norma pueden desvanecerse.

Pues, como tantas veces, el éxito de la ley va a depender en gran medida del acierto en su aplicación, en la que creo que es fundamental también una visión de conjunto, así como una interpretación de la norma basada en gran medida en los principios vertebradores de la misma.

\section{BIBLIOGRAFÍA}

BAÑo LeÓn, J. M. ${ }^{a}$, «El "modificado" de los contratos», en J. M. ${ }^{a}$ Gimeno Feliú (dir.), Estudio sistemático de la Ley de Contratos del Sector Público, Navarra, Thomson Reuters, 2018, pp. 1345-1364.

Bernal Blay, M. A., «Principios de adjudicación de los contratos de servicios de investigación y desarrollo previos a la comercialización (o compra pública precomercial)», en J. M. ${ }^{a}$ Gimeno Feliú y M. A. Bernal Blay (coords.), Observatorio de contratación pública 2013, Navarra, Thomson Reuters, 2014, pp. 233-270.

${ }^{102}$ Es el caso de Cataluña.

${ }^{103}$ De tal modo que, a diferencia de lo que sucediera con la normativa anterior, en palabras de la profesora S. DEL SAL CoRDERO, «La nueva Ley de Contratos del Sector Público. ¿Un nuevo traje con las mismas rayas?», RAP, núm. 174 (2007), pp. 335-366, realmente en esta ocasión creo que sí se ha producido cambios de gran calado. 
Blanco López, F., «Propuesta de regulación legal del procedimiento abierto simplificado», Observatorio de Contratación Pública, 4 de enero de 2016, disponible en bttp://www.obcp.es/index.php/mod.opiniones/mem.detalle/id.217/ relcategoria.121/relmenu.3/chk.511d2896c061bb5c8ec44e0a94272051.

Delgado Fernández, R., «El cálculo del coste de ciclo de vida en la contratación administrativa», Gabilex, núm. 7 (2016), pp. 114-152.

Fernández Acevedo, R., «Negocios y contratos excluidos», en J. M. ${ }^{a}$ Gimeno Feliú (dir.), Estudio sistemático de la Ley de Contratos del Sector Público, Navarra, Thomson Reuters, 2018, pp. 281-323.

Fernández Acevedo, R., y Valcárcel Fernández, P., «La problemática cuestión de la competencia del orden contencioso en relación con los contratos de compra pública precomercial», en Observatorio de los Contratos Públicos. Las nuevas Directivas de Contratación Pública, Navarra, Thomson Reuters, 2015, pp. 265-278.

Franco-García, M. A., «Propósitos y despropósitos sobre los encargos de los poderes adjudicadores a medios propios instrumentales en la Ley de Contratos del Sector Público», Contratación administrativa práctica: revista de la contratación administrativa y de los contratistas, núm. 154 (2018), pp. 6-18.

Gallego Córcoles, I., «Los procedimientos abiertos, restringido, licitación con negociación, negociado sin publicidad y diálogo competitivo», en J. M. ${ }^{\text {a GIME- }}$ NO Feliú (dir.), Estudio sistemático de la Ley de Contratos del Sector Público, Navarra, Thomson Reuters, 2018, pp. 1073-1146.

- «La utilización del procedimiento negociado sin publicidad por razones de exclusividad técnica», Contratación Administrativa Práctica, núm. 149 (2017).

Gimeno Feliú J. M. ${ }^{a}$, «Aproximación a las principales novedades de la Ley de Contratos del Sector Público», Revista Aragonesa de Administración Pública, núm. extra 10 (2008), pp. 13-48.

- «La necesidad de un código de contratos públicos en España. La contratación pública y las PYMES como estrategia de reactivación económica», en J. M. ${ }^{a}$ Gimeno Feliú y M. A. Bernal Blay (coords.), Observatorio de los contratos públicos 2011, Navarra, Civitas, 2012, pp. 27-84.

- «El perfil del comprador europeo: una forma de innovar en contratación pública», Revista de Administración Pública, núm. 192 (2013), pp. 381-400.

- «Transparencia activa e integridad: posibilidades y límites actuales en la legislación de contratos públicos», en J. M. a Gimeno Feliú y M. A. Bernal Blay (coords.), Observatorio de los contratos públicos 2013, Navarra, Thomson Reuters, 2014, pp. 27-80.

- «La nueva Ley de Contratos del Sector Público: una ventana de oportunidad para recuperar el liderazgo institucional público con y desde la contratación pública», Observatorio de Contratación Pública, 23 de octubre de 2017, disponible en bttp://www.obcp.es/index.php/mod.opiniones/mem.detalle/id.317/ relcategoria.208/relmenu.3/chk.d2b802da721758ceee 2 d2c222c7dc305. 
— «La nueva regulación de la contratación pública en España desde la óptica de la incorporación de las exigencias europeas: hacia un modelo estratégico, eficiente y transparente», en J. M. ${ }^{a}$ Gimeno Feliú (dir.), Estudio sistemático de la Ley de Contratos del Sector Público, Navarra, Thomson Reuters, 2018, pp. 47-132.

GonzÁlez García, J., «Medios propios de la Administración, colaboración interadministrativa y sometimiento a la normativa comunitaria de contratación», Revista de Administración Pública, núm. 173 (2007), pp. 217-237.

Guerrero Manso, M. ${ }^{a}$ C. de, «Las consultas preliminares del mercado: una herramienta para mejorar la eficiencia en la contratación pública», en J. M. ${ }^{a}$ GIMENO Feliú (dir.), Estudio sistemático de la Ley de Contratos del Sector Público, Navarra, Thomson Reuters, 2018, pp. 1047-1071.

Hernández Salguero, E., «El nuevo objeto del recurso especial en materia de contratación», en J. M. ${ }^{a}$ Gimeno Feliú (dir.), Estudio sistemático de la Ley de Contratos del Sector Público, Navarra, Thomson Reuters, 2018, pp. 639-666.

Hernando Rydings, M. ${ }^{a}$, «El procedimiento de asociación para la innovación», en J. M. ${ }^{a}$ Gimeno Feliú (dir.), Estudio sistemático de la Ley de Contratos del Sector Público, Navarra, Thomson Reuters, 2018, pp. 1147-1176.

Huergo Lora, A., «La libertad de empresa y la colaboración preferente de las Administraciones Públicas con empresas públicas», Revista de Administración Pública, núm. 154 (2001), pp. 129-174.

López MiÑo, A., «La contratación precomercial en el Derecho de la Unión Europea. El reparto de riesgos y beneficios y la cuestión de las ayudas de Estado», Revista de la Escuela Jacobea de Posgrado, núm. 2 (2012), pp. 73-96.

MarTínez Fernández, J. M., Contratación pública y transparencia. Medidas prácticas para atajar la corrupción en el marco de la nueva regulación, Madrid, El Consultor de los Ayuntamientos, 2016.

- «La imprescindible necesidad de anticipación para afrontar las limitaciones a los contratos menores que impone la nueva Ley de Contratos del Sector Público», El Consultor de los Ayuntamientos y de los Juzgados, núm. 20 (2017), pp. 2425-2439.

Medina Arnáiz, T., «Comentario a los arts. 74 a 78 y 83 a 98», en J. M. Martínez Fernández, Contratación del Sector Público Local, 4. a ed., Madrid, El Consultor de los Ayuntamientos, 2018.

MEnÉNDEZ SebASTIÁN, E. M. ${ }^{a}$, «Régimen jurídico de la contratación pública en Francia», en J. Del Olmo Alonso (dir.), El Derecho de los contratos públicos en la Unión Europea y sus Estados miembros, Valladolid, Lex Nova, 2011, pp. 123-183.

- «La contratación social. Introducción de cláusulas sociales en la contratación pública según la doctrina del TJCE (caso Beetjes y otros)», en E. GARCía DE Enterría y R. Alonso García (coords.), Administración y justicia: un análisis jurisprudencial. Liber Amicorum Tomás-Ramón Fernández, vol. II , Navarra, Thomson-Civitas, 2012, pp. 3403-3428.

- La Administración promotora de la igualdad de género, Valencia, Tirant lo Blanch, 2012. 
- «Virtualidad práctica del recurso especial en materia de contratación pública: una figura inacabada», Revista de Administración Pública, núm. 188 (2012), pp. 365-391.

- «La extinción del contrato: la resolución», en E. Gamero Casado e I. Gallego Córcoles (dirs.), Tratado de Contratos del Sector Público, vol. 3, Valencia, Tirant lo Blanch, 2018, pp. 2381-2412.

Moreno Molina, J. A., El nuevo Derecho de la Contratación Pública de la Unión Europea. Directivas 4.0, Oxford, Chartridge Books Oxford, 2015.

Noguera de la Muela, B., «Los encargos in house en la Ley de Contratos del Sector Público (LCSP): especial referencia a los mismos en el ámbito local a la luz de la reciente jurisprudencia comunitaria», Revista de Administración Pública, núm. 182 (2010), pp. 159-190.

— «El ámbito subjetivo de aplicación de la Ley 9/2017, de 8 de noviembre, de Contratos del Sector Público. Compra conjunta y centrales de compra», en J. M. ${ }^{a}$ Gimeno Feliú (dir.), Estudio sistemático de la Ley de Contratos del Sector Público, Navarra, Thomson Reuters, 2018, pp. 233-280.

Ruiz Daimiel, M., «Tres errores en el nuevo procedimiento abierto simplificado», Observatorio de Contratación Pública, 24 de abril de 2017, disponible en bttp:// www.obcp.es/index.php/mod.opiniones/mem.detalle/id.288/relcategoria.208/ relmenu.3/chk.8901b68b9db71930b37bf38d779c1aef.

SAL Cordero, S. del, «La nueva Ley de Contratos del Sector Público. ¿Un nuevo traje con las mismas rayas?», Revista de Administración Pública, núm. 174 (2007), pp. 335-366.

Santiago Fernández, M. ${ }^{a}$ J., «Procedimiento del recurso especial en materia de contratación», en J. M. ${ }^{a}$ Gimeno Feliú (dir.), Estudio sistemático de la Ley de Contratos del Sector Público, Navarra, Thomson Reuters, 2018, pp. 667-687.

Sanz Cerezo, M. ${ }^{a}$ R., y Martín Gallego, A., «La regulación de los medios propios en la nueva Ley de Contratos del Sector Público», El Consultor de los Ayuntamientos y de los Juzgados, núm. 1 (2018), pp. 111-119.

Sosa Wagner, F., El contrato público de suministro, 2. ${ }^{a}$ ed., Madrid, Civitas, 2003.

- «El empleo de recursos propios por las Administraciones locales», en L. Cosculluela Montaner (coord.), Estudios de Derecho Público Económico. Libro homenaje al profesor S. Martín-Retortillo, Madrid, Civitas, 2007, pp. 1309-1342.

Sosa Wagner, F., y Fuertes LóPez, M., «¿Pueden los contratos quedar en casa? La polémica europea sobre la contratación in house», La Ley, núm. 3 (2007), pp. 1669-1680.

TARDÍO PATO, J. A., «La "asociación para la innovación": contrato, procedimiento de adjudicación y libre competencia», Revista Española de Derecho Administrativo, núm. 181 (2016), pp. 267-295.

Tolivar Alas, L., «Del contrato de suministro», en Comentarios a la Ley de Contratos de las Administraciones Públicas, 2. ${ }^{\text {a }}$ ed., Barcelona, Cedecs, 1996. 